\title{
Colony-Stimulating Factor-1 Antibody Lacnotuzumab in a Phase 1 Healthy Volunteer Study and Mechanistic Investigation of Safety Outcomes $\mathbf{s}$
}

\author{
Francois Pognan, Philippe Couttet, Ivan Demin, Birgit Jaitner, Yinuo Pang, \\ Ronenn Roubenoff, Esther Sutter, Yoav Timsit, Marie Anne Valentin, Beate Vogel, \\ Gaetane Woerly, Armin Wolf, and Ursula Schramm
}

Novartis Pharma AG, Basel, Switzerland (F.P., P.C., I.D., B.J., R.R., E.S., M.A.V., B.V., G.W., A.W., U.S.) and Novartis Institutes for BioMedical Research, Cambridge, Massachusetts (Y.P., Y.T.)

Received October 16, 2018; accepted March 18, 2019

\begin{abstract}
The colony-stimulating factor-1 (CSF-1) receptor pathway has been implicated in a variety of diseases, and CSF-1-dependent mechanisms are also involved in bloodborne protein clearance. Lacnotuzumab is a novel, high-affinity, humanized, anti-CSF-1 monoclonal antibody that prevents CSF-1-mediated receptor activation. This phase 1, two-part, double-blind study in healthy volunteers assessed the safety and tolerability of lacnotuzumab and its pharmacokinetics (PK) and pharmacodynamic properties. Part A $(n=36)$ was a single, ascending-dose assessment of eight lacnotuzumab doses $(0.01-20 \mathrm{mg} / \mathrm{kg})$; in part $\mathrm{B}(n=16)$, lacnotuzumab was administered at either 5 or $10 \mathrm{mg} / \mathrm{kg}$. In each study cohort, individuals were randomized 3:1 to lacnotuzumab or placebo. Lacnotuzumab was generally well tolerated. At higher doses (10 and $20 \mathrm{mg} / \mathrm{kg}$ ), creatine kinase (CK) elevations ( $>5 \times$ the upper limit of normal, but asymptomatic and reversible)
\end{abstract}

and mild transient periorbital swelling were reported. Most adverse events (AEs) were low-grade, no unexpected or novel AEs were observed, and there were no discontinuations for AEs. Free, unbound lacnotuzumab serum concentration-time profiles showed nonlinear PK across doses from 0.01 to $20 \mathrm{mg} / \mathrm{kg}$, with faster apparent elimination at lower doses or concentrations; this finding was consistent with apparent target-mediated drug disposition. Lacnotuzumab also showed dose-dependent, on-target effects on multiple downstream biomarkers. Preclinical investigations of the CK elevation and periorbital swelling observed after lacnotuzumab administration suggest that these are reversible, nonpathological events linked to inhibition of the CSF-1 pathway. These data support further evaluation of lacnotuzumab in clinical studies.

\section{Introduction}

Colony-stimulating factor-1 (CSF-1) is a glycoprotein that, together with its receptor (CSF-1R), is involved in a wide range of cellular processes, including bone metabolism, fertility, embryonic development, immunity, inflammation, tissue repair, and the tumor microenvironment (Fixe and Praloran, 1997; Stanley and Chitu, 2014). Activation of CSF-1R by CSF-1 triggers a series of rapid events, including receptor dimerization and phosphorylation, as well as association of the intracellular receptor domain with a variety of cytoplasmic effector proteins. These events in turn activate multiple signal transduction pathways controlling proliferation, differentiation, survival, and migration of monocytes and macrophages (Pixley and Stanley, 2004; Stanley and Chitu, 2014).

This work was supported by Novartis.

https://doi.org/10.1124/jpet.118.254128.

S This article has supplemental material available at jpet.aspetjournals.org.
The CSF-1/CSF-1R signaling pathway has been implicated in a variety of diseases. Inappropriate overexpression of CSF-1/CSF-1R has been documented in breast, prostate, and ovarian cancer and in classic Hodgkin lymphoma (Achkova and Maher, 2016). CSF-1R signaling was also found to enhance the invasion and metastasis of solid tumors (Dwyer et al., 2017). Furthermore, aberrant CSF-1/CSF-1R signaling has been implicated in several inflammatory conditions, such as rheumatoid arthritis (RA) (Garcia et al., 2016), Crohn disease (Nieto et al., 2017), lupus nephritis (Menke et al., 2009), cutaneous lupus erythematosus (Menke et al., 2008), and pigmented villonodular synovitis (PVNS) (Brahmi et al., 2016; Staals et al., 2016). Indeed, PVNS has been shown to be directly related to overexpression of CSF-1 (West et al., 2006; Cupp et al., 2007). Macrophages expressing CSF-1R, especially Kupffer cells in the liver, play a role in the clearance of enzymes from the circulation, including alanine aminotransferase (ALT), aspartate aminotransferase (AST), lactate dehydrogenase, and creatine kinase (CK) (Horiuchi et al., 1985;

ABBREVIATIONS: ADA, antidrug antibodies; AE, adverse event; ALP, alkaline phosphatase; AST, aspartate aminotransferase; CK, creatine kinase; CSF-1, colony-stimulating factor-1; CTX-I, serum collagen type 1 cross-linked C-telopeptide; DLT, dose-limiting toxicity; ECG, electrocardiogram; GMR, geometric mean ratio; LLOQ, lower limit of quantification; MTD, maximum-tolerated dose; OPG, osteoprotegerin; PAS, periodic acid-Schiff; PD, pharmacodynamics; PINP, amino-terminal propeptide of type 1 procollagen; PK, pharmacokinetics; PVNS, pigmented villonodular synovitis; RA, rheumatoid arthritis; TMDD, target-mediated drug disposition; TRAP5b, tartrate-resistant acid phosphatase 5b; ULN, upper limit of normal. 
Kamimoto et al., 1985; Smit et al., 1986, 1987, 1988). The presence of these enzymes in the circulation is determined by normal cell turnover, enzyme leakage from various organs, and enzyme elimination rate. These factors thus determine the half-lives of circulating enzymes. Tissue damage from disease or toxicity, for example, results in enzyme leakage, with corresponding increases in enzyme activity and enzyme levels in plasma or serum. These enzymes are commonly used as biomarkers of hepatic (ALT, AST, and lactate dehydrogenase) or muscle and heart (CK) disease or toxicity (Campion et al., 2013). Usually, only an increase in net values above the normal range is considered when assessing these safety biomarkers. The increase is interpreted as resulting from increased cell leakage and as evidence of tissue damage; reduction in the clearance of these enzymes is often overlooked; however, data from the experimental depletion of Kupffer cells or the disruption of CSF-1 in animal models suggest that decreased biomarker clearance can be the cause of net enzyme elevation, despite the complete absence of organ adverse events (AEs) (Dillberger et al., 1987; Hayashi et al., 1988; Radi et al., 2011; Wang et al., 2011). This finding may have implications in terms of assessing these biomarkers as AEs when the CSF-1 pathway is targeted for clinical intervention.

Given the role that CSF-1 plays in a range of different diseases, several pharmacologic agents targeting the CSF-1 pathway have been developed (Cannarile et al., 2017). These include selective CSF-1R kinase inhibitors, such as JNJ-40346527 (Genovese et al., 2015), pexidartinib (PLX3397) (Tap et al., 2015), BLZ945 (https://clinicaltrials.gov/ct2/show/NCT02829723; Pyonteck et al., 2013), and the CSF-1R-targeting monoclonal antibodies emactuzumab (RG7155) (Cassier et al., 2015) and cabiralizumab (FPA008) (https://clinicaltrials.gov/ ct2/show/NCT02471716; https://clinicaltrials.gov/ct2/show/ NCT02526017). These CSF-1R inhibitors have undergone clinical trials in patients with RA, PVNS, and advanced solid tumors. The nonselective tyrosine kinase inhibitors with activity against CSF-1R, imatinib (Cassier et al., 2012; Stacchiotti et al., 2013) and nilotinib (https://clinicaltrials.gov/ ct2/show/NCT01207492; https://clinicaltrials.gov/ct2/show/ NCT01261429), have also been investigated in patients with PVNS. An antibody against CSF-1, PD-0360324, has been tried in RA (https://clinicaltrials.gov/ct2/show/NCT00550355), lupus erythematosus (Masek-Hammerman et al., 2016), and pulmonary sarcoidosis (https://clinicaltrials.gov/ct2/show/NCT01732211). In these studies, the AEs of periorbital edema or swelling and raised circulating enzyme or CK levels were observed (Cassier et al., 2012, 2015; Genovese et al., 2015; Tap et al., 2015; MasekHammerman et al., 2016; Cannarile et al., 2017). These AEs appear to be typical of agents targeting the CSF-1 pathway and have hindered the clinical development of therapies in this area. We investigated the hypothesis that raised CK levels are a consequence of Kupffer cell depletion in the liver as opposed to treatment-related organ injury or toxicity (Radi et al., 2011; Wang et al., 2011).

Lacnotuzumab (MCS110) is a novel high-affinity, humanized IgG1/ $\kappa$ monoclonal antibody targeting CSF- 1 that prevents CSF-1 from activating the CSF-1R (Pryer et al., 2009; Calvo et al., 2018). We conducted a phase 1 study to assess the safety and tolerability of administering single ascending doses and repeat doses of lacnotuzumab to healthy volunteers and to examine the pharmacokinetics (PK), pharmacodynamics (PD), and mechanistic properties of lacnotuzumab. Nonclinical investigations of the mechanism of action of lacnotuzumab were also performed to explain the observed $\mathrm{AE}$ profile associated with CSF-1 pathway inhibition.

\section{Materials and Methods}

\section{Clinical Study in Human Volunteers}

The clinical study protocol and all amendments were reviewed and approved by the Institutional Review Board of each participating study center. Informed consent from each participant was obtained in writing prior to randomization. The study was conducted in accordance with Good Clinical Practice and the ethical principles of the Declaration of Helsinki.

\section{Study Design}

The clinical trial was a phase 1, two-part, double-blind, randomized, placebo-controlled study conducted in healthy volunteers between August 2010 and May 2013. The randomization scheme was generated with a validated system; randomization numbers were assigned in ascending, sequential order to eligible participants in accordance with entry into the study. The central randomization code was maintained by an independent person for competitive recruitment. After a 3-week screening period, participants were assigned to one of 10 cohorts and randomized 3:1 to receive lacnotuzumab or placebo via 1-hour intravenous infusion. The participants were followed up for up to 15 weeks (cohorts 1-8), 18 weeks (cohort 9), or 1 year (cohort 10) (Supplemental Fig. 1). All individuals were monitored in-clinic for 48 hours postdose. Treatment allocation and clinical assessment were blind for both participants and investigators, with treatment allocation cards sent to the pharmacist at each study site; the appearances of the placebo and lacotuzumab treatments were identical for all cohorts.

Part A, which involved cohorts 1-8, used a single, ascending-dose assessment to determine the maximum-tolerated dose (MTD) and dose-limiting toxicities (DLTs) of lacnotuzumab (0.01, 0.03, 0.1, 0.3, 1, 3,10 , and $20 \mathrm{mg} / \mathrm{kg}$ ). The follow-up period was 105 days. The sample size for each cohort in part A (three treated, one placebo) was chosen to proceed cautiously, reviewing data from one dose level before dosing the next higher dose. The starting dose level of $0.01 \mathrm{mg} / \mathrm{kg}$ was tested in a phase 1/2 trial (CMCS110A2101) (https://clinicaltrials.gov/ct2/ show/NCT00757757); no drug-related AEs were observed after multiple intravenous infusions, except for a transient infusion-related reaction in one of three patients after the first dose. A single intravenous infusion of $0.01 \mathrm{mg} / \mathrm{kg}$ was expected to achieve an initial target occupancy of approximately $78 \%$ at the initial $C_{\max }$ $(\sim 0.25 \mu \mathrm{g} / \mathrm{ml})$. After intravenous $0.01 \mathrm{mg} / \mathrm{kg}$ administration in the CMCS110A2101 study, free lacnotuzumab was eliminated from the body within 8 hours postinfusion. In summary, $0.01 \mathrm{mg} / \mathrm{kg}$ was considered a viable starting dose for healthy volunteers in our study. The human efficacious doses were expected to be in the range of 1-20 mg/kg, after multiple intravenous doses, to maintain a serum concentration of at least 5-10 $\mu \mathrm{g} / \mathrm{ml}$. This assumption was based on PD data from a PK/PD study in monkeys, in which a sustained suppression of bone resorption markers was observed with weekly intravenous infusions of lacnotuzumab at a dose of $10 \mathrm{mg} / \mathrm{kg}$.

In each cohort, lacnotuzumab was administered initially to just two subjects, who were observed for $\geq 24$ hours before the next two subjects were dosed. All individuals within a cohort were observed for $\geq 14$ days postdose before the next cohort was dosed. Once the MTD was reached in part A (cohorts 1-8), a safety review team conducted a prespecified interim analysis to select the dose for use in the first cohort of part B (cohort 9). The selected dose was $5 \mathrm{mg} / \mathrm{kg}$, and the selected dosing interval was 21 days.

In part B (cohorts 9 and 10), a repeat-dose assessment was used to determine the safety, tolerability, and pharmacokinetics of lacnotuzumab after two doses; the follow-up period was 127 days. The plan was for cohort 9 to receive two doses of lacnotuzumab at onehalf the MTD determined in part A, with a dosing interval of 21, 28, or 
35 days, depending on the findings of the safety review team at the end-of-part-A interim analysis. Cohort 10 was to receive two doses of lacnotuzumab at the MTD, administered 56 days apart.

\section{Participants}

Adult men and women aged 18-50 years (females, postmenopausal or with reported surgical sterilization) considered in good health based on medical history, physical examination, vital signs, electrocardiogram (ECG) results, and laboratory tests at screening were eligible for inclusion. In addition, female participants must have had negative pregnancy test results at screening and baseline or be postmenopausal for $\geq 1$ year before initial dosing; male participants were required to use appropriate contraception throughout the study.

Exclusion criteria included smoking $\geq 10$ cigarettes per day, use of any prescription drugs or herbal supplements within 4 weeks or of over-the-counter medication or dietary supplements within 2 weeks before initial dosing, major surgery $\leq 3$ months before initial dosing, participation in any other clinical investigation within 30 days (or four half-lives of the intervention in question) after discontinuing study treatment, donation or loss of $\geq 400 \mathrm{ml}$ of blood within 8 weeks before initial dosing, hemoglobin levels $<12.0 \mathrm{~g} / \mathrm{dl}$ at screening, any history of coagulation disorders, significant illness within 2 weeks before initial dosing, and engagement in regular training programs (body building).

\section{Study Objectives}

The primary objectives of the study were to characterize the DLTs of single ascending doses of lacnotuzumab (part A) and determine the safety and tolerability of repeated doses of lacnotuzumab (part B). Secondary study objectives were to characterize the PK of single and repeat doses of lacnotuzumab; assess the effect of lacnotuzumab on plasma total CSF-1 (sum of free and lacnotuzumab-bound CSF-1) and soluble CSF-1R levels; assess the effects of lacnotuzumab on markers of bone resorption [serum collagen type 1 cross-linked C-telopeptide (CTX-I) and tartrate-resistant acid phosphatase 5b (TRAP5b)], bone formation [serum osteocalcin, bone-specific alkaline phosphatase (ALP), and amino-terminal propeptide of type 1 procollagen (PINP)], and calcium and phosphate metabolism (intact parathyroid hormone, $\mathrm{Ca}^{2+}, \mathrm{PO}_{4}{ }^{3-}, 25$-hydroxyvitamin $\mathrm{D}$, and calcitonin); and assess the immunogenicity of lacnotuzumab. Exploratory objectives included the assessment of factors known to be involved in bone metabolism [osteoprotegerin (OPG) and receptor activator for nuclear factor к-B ligand] after administration of lacnotuzumab and evaluation of changes in the major populations of leukocytes, including the levels of circulating CD14+ and CD14+CD16+ monocytes.

\section{Study Assessments}

Full details of the evaluation schedules and assays used for each clinical assessment can be found in the Supplemental Methods section of the Supplemental Material. Safety assessments included regular monitoring of blood and urine chemistry; regular evaluation of vital signs, cardiac parameters, and tests (including ECGs and CK), physical condition, and body weight; recording of all AEs and serious AEs; and evaluation of lacnotuzumab immunogenicity. For PK and PD analyses, free (unbound to CSF-1) lacnotuzumab serum concentrations and total (free plus lacnotuzumab-bound) CSF-1 plasma concentrations were determined from blood samples using validated enzyme-linked immunosorbent assay. Soluble CSF-1R concentrations in serum were determined using a validated sandwich enzyme-linked immumunosorbent assay. The affinity of the binding interaction between lacnotuzumab and human CSF-1 ranges from 400 to $550 \mathrm{pM}$ (average: $480 \mathrm{pM}$ ) and was determined using a Biacore 2000 analyzer. The principal activity and potency assay for lacnotuzumab measured the ability of the antibody to inhibit CSF-1-driven proliferation of the mouse myelogenous leukemia cell line M-NFS-60. The antibody concentration that blocked $50 \%$ of the proliferative response $\left(\mathrm{IC}_{50}\right)$ over multiple repeats of the assay was $10-20 \mathrm{ng} / \mathrm{ml}$. Lacnotuzumab neutralizes recombinant and serum-derived forms of cynomolgus and human CSF-1 with approximately equal potency, but it does not recognize rodent or rabbit CSF-1. To assess immunogenicity, the presence of antilacnotuzumab antibodies was evaluated using a validated three-tiered electrochemiluminescence assay approach on the Meso Scale Discovery platform (Meso Scale Diagnostics, Rockville, MD) (Supplemental Methods).

Fasting blood samples were obtained for assessment of soluble biomarkers. Biomarkers of bone resorption (CTX-I and TRAP5b), bone metabolism (osteocalcin, bone-specific ALP, and PINP), and calcium/ phosphate metabolism (OPG, intact PTH, 25-hydroxyvitamin D, and calcitonin) were measured in serum using validated immunoassays. Leukocyte subsets (including CD3+, CD4+, and CD8+ T cells; CD19+ B lymphocytes; natural killer cells; granulocytes; and CD14+ and CD14+CD16+ monocytes) were measured in whole blood by fluorescence-activated cell sorting. Details of the antibodies used in the fluorescence-activated cell sorting analysis are given in Supplemental Table 1.

Lacnotuzumab serum concentration-time data were analyzed using the noncompartmental PK method in Phoenix WinNonlin version 6.3 (Certara USA, Princeton, NJ). In addition, PD data for four biomarkers (CTX-I, circulating CD14+ monocytes, circulating CD14+CD16+ monocytes, and serum CK) from the study were used for dose-exposure-response modeling. A nonlinear, mixed-effects approach was applied and implemented using Monolix 4.1.3 (Lixoft, Antony, France). Sequential population PK/PD analyses were implemented using the population PK parameters and data approach (i.e., including PK data but estimating only PD parameters) (Zhang et al., 2003). Using the established PK/PD models, the steady-state doseresponse relationships were simulated (dose range: $0.3-20 \mathrm{mg} / \mathrm{kg}$ with administration every 4 weeks). Simulations were performed using Monolix 4.1.3; all figures were produced in $\mathrm{R}$ (version 2.13.2) using ggplot2, version 0.8.9.

\section{Nonclinical Mechanistic Investigation of CK Elevation and Periorbital Swelling}

To better understand the mechanisms behind the CK elevations and periorbital swelling observed with lacnotuzumab, two studies were carried out in cynomolgus monkeys (Macaca fascicularis).

Investigation of CK Elevation. The first study was a 4-week investigative trial of the elimination kinetics of exogenous histidinetagged (His-tagged) cynomolgus CK, muscle type (CK-M), and the plasma level of microRNAs as specific markers of liver (miR-122), heart (miR-1), and skeletal muscle (miR-1 plus miR-206, miR-486-5p, miR-486-3p) injury/toxicity, before and after a single dose of lacnotuzumab in five monkeys (conducted by Novartis Pharmaceuticals Company, East Hanover, NJ). The second study was a 26 -week good laboratory practice toxicity trial of once-weekly lacnotuzumab dosing ( $n=40$ animals) with a 38-week recovery period (conducted by Covance Preclinical Services GmbH, Muenster, Germany) in which periorbital swelling was examined histologically. All animals received humane care according to local welfare laws and guidelines, and the studies were conducted in compliance with US and EU animal health regulations, as outlined in the "Guide for the Care and Use of Laboratory Animals" prepared by the National Academy of Sciences and published by the National Institutes of Health (NIH publication 86-23 revised 1985) and the Council Directive No. 2010/63/EU of September 22, 2010 on the protection of animals used for scientific purposes, respectively (Supplemental Methods).

In brief, His-tagged CK-M was intravenously administered at a dose of $66.7 \mu \mathrm{g} / \mathrm{kg}$ on day 1 and day 22; application volume was $1 \mathrm{ml} / \mathrm{kg}$. Lacnotuzumab was intravenously administered at a dose of $20 \mathrm{mg} / \mathrm{kg}$ at $1 \mathrm{ml} / \mathrm{kg}$ on day 8 . Blood samples were collected periodically over 48 hours after a single injection of His-tagged CK-M administered on day 1 and day 22 for His-tagged CK-M analysis. All animals were returned to their housing alive. Plasma from the blood samples was used for His-tagged CK-M determination 
and microRNA analysis. HIS-Select Nickel Affinity gel P6611-5ML (Sigma-Aldrich, St. Louis, MO) was used to capture His-tagged CK-M from plasma, and the enzymatic activity was assayed according to a standard protocol (Thermo Protocol TR14115; Thermo Fisher Scientific, Waltham, MA), expressed as units per liter. Reported values are means of triplicate determinations. MicroRNA levels were assessed from plasma at pretest and at the end of the study. Small RNA was extracted from $50 \mu \mathrm{l}$ of plasma by using the RNeasy/MinElute kit (Qiagen Sciences, Germantown, MD), and microRNAs were amplified by TaqMan assay (Applied Biosystems/ThermoFisher Scientific, Waltham, MA) according to the manufacturers' instructions.

Investigation of Periorbital Swelling. In the 26-week good laboratory practice toxicity study, lacnotuzumab was administered by intravenous (slow bolus) infusion to three groups (six or four animals per sex in each group) of cynomolgus monkeys at a daily dose of $0.2,20$, or $100 \mathrm{mg} / \mathrm{kg}$ for $\geq 26$ weeks (total of 26 doses). A control group of cynomolgus monkeys (six animals per sex) were administered the same buffer composition without lacnotuzumab (control solution) at an equivalent dose volume. Two animals/sex administered $20 \mathrm{mg} / \mathrm{kg}$ or control were maintained on study for a 38 -week recovery phase. Briefly, possible periorbital swelling was monitored during the study, with photos taken of both eyes before dosing; additional photos were taken as soon as an observation of periorbital swelling was made, together with follow-up photos. Electronic pictures were for illustrative purposes only. Tissue samples from selected organs, including the eyelid/eye bag, were taken at the planned necropsy of the main and recovery periods and stored in 10\% neutral buffered formalin. In addition to routine hematoxylin and eosin staining, tissue sections of the eyelid/eye bag were stained with Alcian blue $\mathrm{pH} 2.5$, Alcian blue $\mathrm{pH} 0.5$, and periodic acid-Schiff (PAS) (ProPath Ltd, Hereford, UK) to identify the nature of the observed accumulation of basophilic material correlating with the periorbital swelling.

Full details for both monkey studies can be found in the Supplemental Methods section of the Supplemental Data.

\section{Statistical Analyses}

Clinical Study in Human Volunteers. For clinical study part A, a sample size of three individuals receiving treatment and one receiving placebo per dose level was chosen to enable data to be reviewed from one dose level before proceeding with dosing at the next (higher) level. It was hypothesized that if one of six individuals experienced a DLT at the MTD, then the probability that the dose toxicity is acceptable is $74 \%$. Likewise, a sample size of just six subjects receiving treatment and two receiving placebo per dose level was chosen for part B. Data from part A (cohorts 1-8) and part B (cohorts 9 and 10) were analyzed separately.

The safety analysis set included all randomized individuals who received $\geq 1$ dose of study drug. The PK analysis set included all individuals who had data for $\geq 1$ of the primary $\mathrm{PK}$ variables and no major protocol deviations that would impact PK data. The PD analysis set included all subjects with available PD data who had no major protocol deviations that would impact PD data. Summary statistics were generated for all applicable primary variables; descriptive statistics were generated for key secondary variables: $\mathrm{PK}, \mathrm{PD}$, and biomarkers of bone remodeling and metabolism. Two interim analyses of safety data were performed: one upon completion of part $A$ and before the initiation of part $\mathrm{B}$ and one after the last dose of the second cohort in part B.

Handling of Missing Data. Missing safety data were reported as such in the data listings and excluded from summaries. Concentrations below the lower limit of quantification (LLOQ) or where there were missing data were labeled as such in the concentration data listing; those below the limit of quantification were treated as zero in summary statistics and for the calculation of PK parameters. Biomarker values below the LLOQ or missing data were labeled as such in the data listings and were replaced by LLOQ/2 in calculations and summaries. End of study PD data were flagged for exclusion for subjects who discontinued early.
Preclinical Investigation of CK and Periorbital Swelling. In the study of CK-M clearance in monkeys, differences in His-tagged protein kinetics between treatment groups were assessed using repeated-measures two-way analysis of variance with post hoc Sidak multiple comparison test ( $\alpha=0.05$ ); $P$ values $<0.05$ were considered statistically significant. The relative quantification of microRNA levels was performed using the standard curve method, and expression values were determined as copy number. Statistical significance was assessed using the two-sample unequal variance and two-tailed distribution Student's $t$ test. Results with a $P$ value $<0.05$ were considered statistically significant.

\section{Results}

Participant Disposition, Demographics, and Baseline Characteristics. A total of 36 adults were enrolled and randomized to treatment in part A (lacnotuzumab, $n=27$; placebo, $n=9$ ), and 32 completed the study (Fig. 1). In part B, 16 individuals were enrolled and randomized into either cohort 9 (lacnotuzumab, $n=6$; placebo, $n=2$ ) or cohort 10 (lacnotuzumab, $n=6$; placebo, $n=2$ ); five individuals from cohort 9 and one from cohort 10 completed the study (Fig. 1; Supplemental Fig. 1). Except for two individuals in cohort 10, all study discontinuations were from the lacnotuzumab treatment arms. In cohorts $1-8$, one individual in the $0.01 \mathrm{mg} / \mathrm{kg}$ group discontinued from the study on day 28 , two from the $0.03 \mathrm{mg} / \mathrm{kg}$ group discontinued on day 65 and day 99 , respectively, and one from the $1 \mathrm{mg} / \mathrm{kg}$ group discontinued on day 104. From cohort 9, two subjects received only one dose each and were lost to follow-up at days 36 and 128, respectively. Four subjects received two doses of lacnotuzumab, and one of these discontinued from the study on day 126. All those in cohort 10 received one dose of $10 \mathrm{mg} / \mathrm{kg}$ or up to two doses of placebo. Of those receiving lacnotuzumab, five of the six participants discontinued early at days $42,43,78,92$, and 93; the two receiving placebo also discontinued early at days 127 (one dose) and 163 (two doses), respectively. Baseline characteristics of study participants were similar across the cohorts. In parts A and B, participants were predominantly men $(97 \%$ and $88 \%$, respectively) and white $(72 \%$ and $75 \%$, respectively), with a mean age of 30.1 years (part A) and 29.5 and 31.6 years (part B, cohorts 9 and 10, respectively) (Tables 1 and 2).

Dose Escalation. In part A, increases in $\mathrm{CK}>5 \times$ the upper limit of normal (ULN) were recorded in three participants who received lacnotuzumab $20 \mathrm{mg} / \mathrm{kg}$ (cohort 8). Accordingly, this cohort was stopped, and cohort 7 was expanded so that six participants received lacnotuzumab $10 \mathrm{mg} / \mathrm{kg}$, and two received placebo.

Once enrollment was completed in cohorts 1-8 (part A), a safety review team conducted the prespecified interim analysis to select the dose and dosing interval for cohort 9 (part B). A dose of $5 \mathrm{mg} / \mathrm{kg}$ (i.e., one-half the MTD) was therefore selected for cohort 9 , to be administered twice with a dosing interval of 21 days; however, two participants in cohort 9 experienced increases in CK $>5 \times$ ULN after receiving two doses of lacnotuzumab $5 \mathrm{mg} / \mathrm{kg}$.

The PK and total CSF-1 profiles of individuals in cohort $7(10 \mathrm{mg} / \mathrm{kg}$ dose $)$ indicated sustained target suppression for 56 days. This finding was supported by a lack of modeled CK accumulation at a $10 \mathrm{mg} / \mathrm{kg}$ dose over the same time frame. Therefore, the safety review team selected a dose of $10 \mathrm{mg} / \mathrm{kg}$ 


\section{A (cohorts 1 to 8 )}

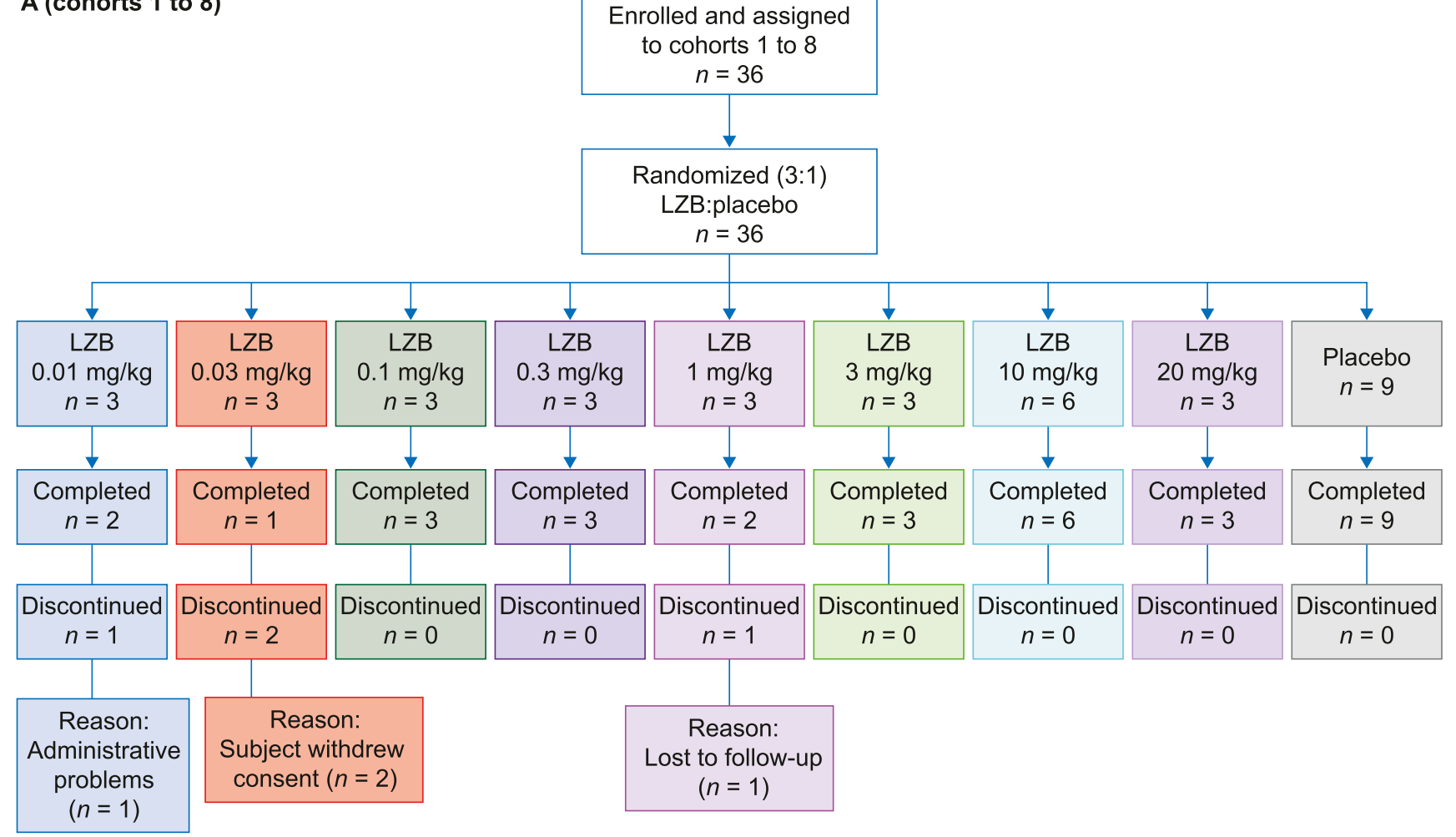

\section{B (cohorts 9 and 10)}
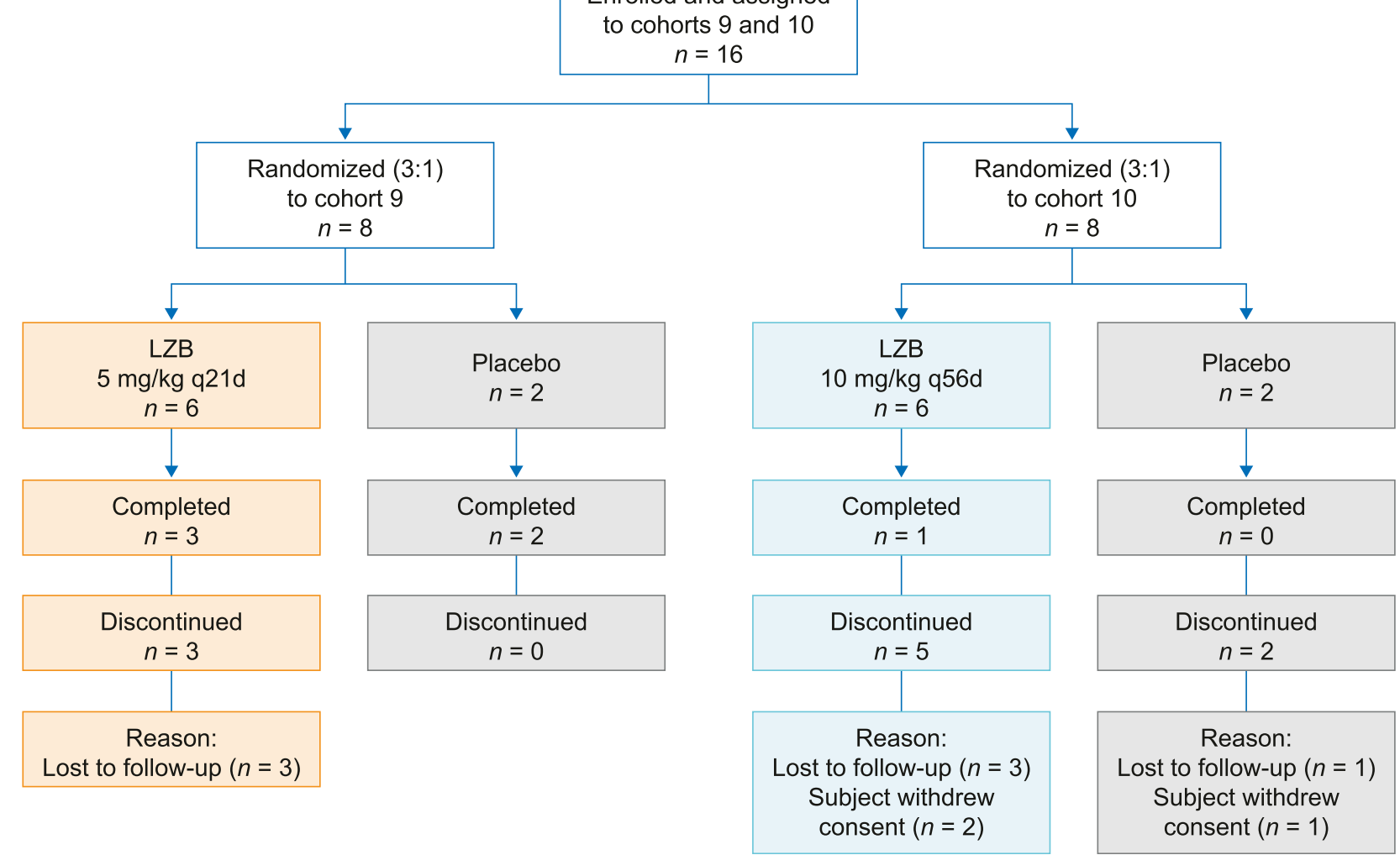

Fig. 1. Patient flow. (A) Cohort 7 was expanded so that six individuals received LZB $10 \mathrm{mg} / \mathrm{kg}$, and two received placebo after three individuals who received LZB $20 \mathrm{mg} / \mathrm{kg}$ (cohort 8) recorded creatine kinase increases >5× ULN. LZB, lacnotuzumab; q21d, every 21 days; ULN, upper limit of normal. 


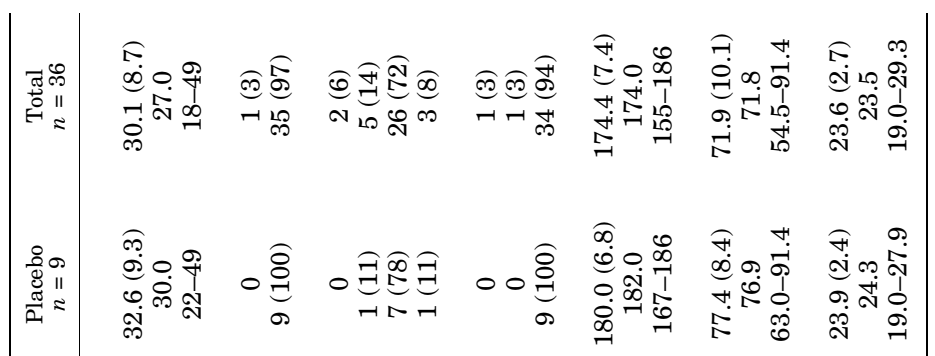

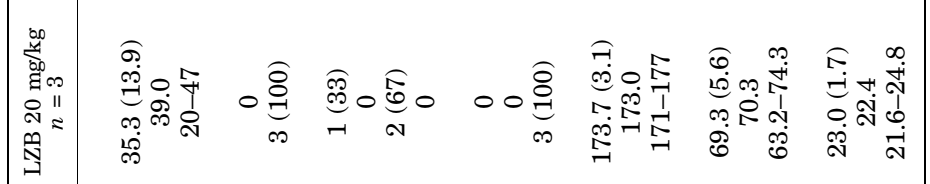

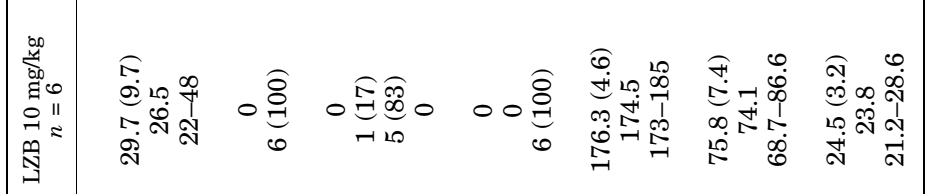

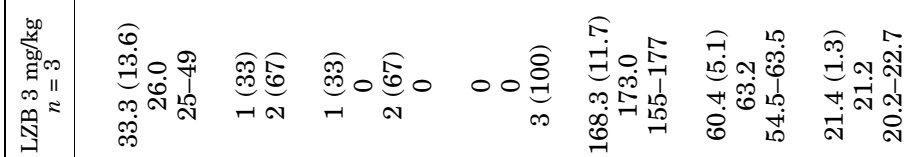

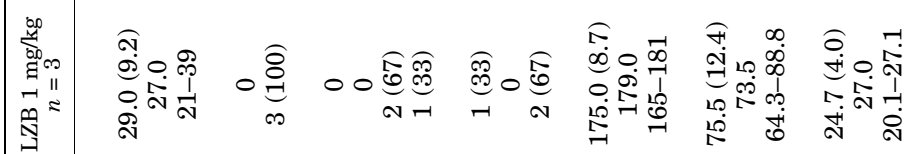

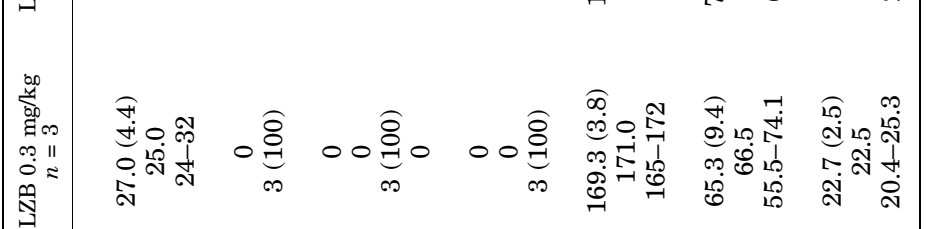

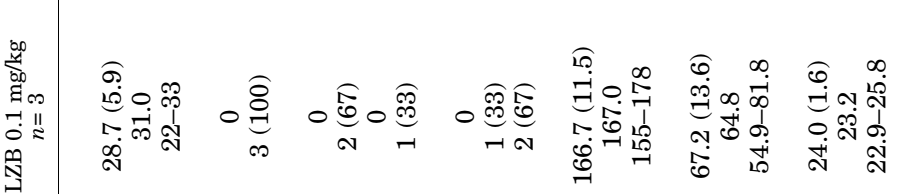

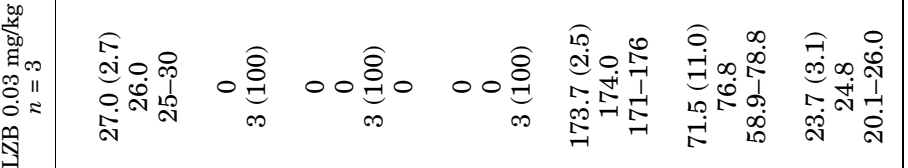

要

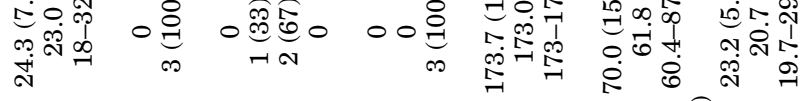


TABLE 2

Baseline demographics (safety analysis set) cohorts 9 and 10

\begin{tabular}{|c|c|c|c|c|c|c|}
\hline & $\underset{n=6}{\text { LZB } 5 \underset{n g}{\mathrm{mg} / \mathrm{kg} \text { q21d }}}$ & $\begin{array}{c}\text { Placebo } \\
n=2\end{array}$ & $\begin{array}{l}\text { Total } \\
n=8\end{array}$ & $\begin{array}{l}\text { LZB } 10 \mathrm{mg} / \mathrm{kg} \mathrm{q} 56 \mathrm{~d} \\
n=6\end{array}$ & $\begin{array}{c}\text { Placebo } \\
n=2\end{array}$ & $\begin{array}{l}\text { Total } \\
n=8\end{array}$ \\
\hline \multicolumn{7}{|l|}{ Age (yr) } \\
\hline Mean (S.D.) & $27.3(11.5)$ & $36.0(0.0)$ & $29.5(10.5)$ & $35.7(14.7)$ & $19.5(0.7)$ & $31.6(14.5)$ \\
\hline Median & 23.0 & 36.0 & 30.5 & 36.5 & 19.5 & 23.5 \\
\hline Range & $18-47$ & $36-36$ & $18-47$ & $20-50$ & $19-20$ & $19-50$ \\
\hline \multicolumn{7}{|l|}{ Sex, $n(\%)$} \\
\hline Female & $1(17)$ & 0 & $1(13)$ & $1(17)$ & 0 & $1(13)$ \\
\hline Male & $5(83)$ & $2(100)$ & $7(88)$ & $5(83)$ & $2(100)$ & $7(88)$ \\
\hline \multicolumn{7}{|c|}{ Predominant race, $n(\%)$} \\
\hline Asian & 0 & 0 & 0 & 0 & 0 & 0 \\
\hline Black & $2(33)$ & 0 & $2(25)$ & $2(33)$ & 0 & $2(25)$ \\
\hline White & $4(67)$ & $2(100)$ & $6(75)$ & $4(67)$ & $2(100)$ & $6(75)$ \\
\hline Other & 0 & 0 & 0 & 0 & 0 & 0 \\
\hline \multicolumn{7}{|l|}{ Ethnicity, $n(\%)$} \\
\hline Hispanic/Latino & $1(17)$ & 0 & $1(13)$ & $6(100)$ & $2(100)$ & $8(100)$ \\
\hline Mixed ethnicity & 0 & 0 & 0 & 0 & 0 & 0 \\
\hline Other & $5(83)$ & $2(100)$ & $7(88)$ & 0 & 0 & 0 \\
\hline \multicolumn{7}{|l|}{ Height $(\mathrm{cm})$} \\
\hline Mean (S.D.) & $171.0(8.4)$ & $176.5(5.0)$ & $172.4(7.8)$ & $177.3(9.5)$ & $180.0(1.4)$ & $178.0(8.1)$ \\
\hline Median & 168.0 & 176.5 & 168.5 & 176.0 & 180.0 & 179.0 \\
\hline Range & $166-188$ & $173-180$ & $166-188$ & 165-192 & $179-181$ & 165-192 \\
\hline \multicolumn{7}{|l|}{ Weight (kg) } \\
\hline Mean (S.D.) & $76.1(12.4)$ & $81.6(12.6)$ & $77.5(11.8)$ & $81.1(11.3)$ & $64.6(2.6)$ & $77.0(12.3)$ \\
\hline Median & 75.8 & 81.6 & 75.8 & 81.3 & 64.6 & 73.9 \\
\hline Range & $58.6-96.8$ & $72.7-90.5$ & $58.6-96.8$ & 69.5-99.5 & $62.7-66.4$ & 62.7-99.5 \\
\hline \multicolumn{7}{|c|}{ Body mass index $\left(\mathrm{kg} / \mathrm{m}^{2}\right)$} \\
\hline Mean (S.D.) & $25.9(2.6)$ & $26.1(2.6)$ & $26.0(2.4)$ & $25.7(1.9)$ & $19.9(1.1)$ & $24.3(3.1)$ \\
\hline Median & 26.7 & 26.1 & 26.7 & 25.5 & 19.9 & 24.9 \\
\hline Range & $20.8-28.1$ & $24.3-27.9$ & $20.8-28.1$ & $23.2-28.6$ & $19.1-20.7$ & $19.1-28.6$ \\
\hline
\end{tabular}

LZB; lacnotuzumab; q21d, every 21 days; q56d, every 56 days; SD, standard deviation.

for cohort 10 , to be dosed twice with a 56-day dosing interval. After administration of the first dose of lacnotuzumab $10 \mathrm{mg} / \mathrm{kg}$ in cohort 10 , increases in CK $>5 \times$ ULN were reported in four individuals. In parallel, four of the six subjects in cohort 10 developed mild transient periorbital swelling (a predefined DLT) after the first dose and therefore did not receive a second lacnotuzumab dose. Given these findings, no participants in cohort 10 went on to receive a second dose of lacnotuzumab $10 \mathrm{mg} / \mathrm{kg}$.

Clinical Laboratory Findings and Vital Signs. There were no clinically significant changes in urinalysis, hematology parameters, coagulation parameters, or clinical chemistry except elevated AST, which occurred in 24 individuals. Maximum increases in AST were $\leq 2 \times$ ULN in 16 subjects and $\leq 3 \times$ ULN in eight. Elevations tended to occur by day 8 , lasting until day 22,29 , or 57 . Sixteen participants experienced elevated CK during the study. The CK elevations were asymptomatic, and most events resolved by the end of the study with no concomitant treatment.

One individual (cohort 10) experienced a clinically significant change in ECG (prolonged QT interval, grade 1) on day 43. This finding was not suspected to be related to study treatment and resolved approximately 15 days after onset. Clinically significant changes in vital signs occurred in only two individuals. One participant receiving placebo in part A experienced grade 1 pyrexia on day 46 (body temperature: $37.9^{\circ} \mathrm{C}$ ). The $\mathrm{AE}$ had resolved by the next day without any concomitant treatment; the individual's body temperature remained normal throughout the rest of the study, and the $\mathrm{AE}$ was not considered related to the study drug. One participant receiving lacnotuzumab in part B (cohort 10) reported an increased heart rate (grade 2) and decreased systolic blood pressure (grade 2 ) on day 1 . These findings were considered related to the study drug, whose administration was temporarily interrupted. Both events resolved within 1 hour.

PK Results. After a single intravenous infusion of lacnotuzumab, nonlinear PK of free lacnotuzumab in serum was observed across dose ranges (Fig. 2; Table 3). There was rapid clearance at lower doses or concentrations and slower clearance and more sustained exposure at higher doses or concentrations. Terminal elimination half-life also increased with dose, indicating a longer residence time and lower apparent elimination rate at higher doses or concentrations. These nonlinear PK profiles were consistent with the apparent target-mediated drug disposition (TMDD) of lacnotuzumab, whereby binding of lacnotuzumab to its target (CSF-1) causes it to be no longer detected in the "free" lacnotuzumab assay, which detects only unbound lacnotuzumab. After two intravenous infusions of lacnotuzumab $5 \mathrm{mg} / \mathrm{kg}$ on days 1 and 22 , a moderate accumulation of free lacnotuzumab concentration was noted in the serum (geometric mean ratio [GMR]: 1.29) (Supplemental Table 2). As in the single-dose profiles, nonlinear profiles consistent with TMDD were observed, with more rapid clearance at lower doses or concentrations (Fig. 2).

PD and Mechanistic Effects. Plasma total CSF-1 increased in a dose-dependent manner after administration of lacnotuzumab, but it remained similar to the predose (baseline) levels in the group who received placebo (Supplemental Fig. 2). The increase in total plasma CSF-1 was presumably due to slower clearance of CSF-1 complexed to lacnotuzumab, indicating successful target engagement. Plasma total CSF-1 remained elevated relative to baseline at the end-of-study visit for all those treated with lacnotuzumab in part A. An eventual decline toward baseline values was observed in the one individual for whom data were collected up to 280 days postdose. No apparent dose-related changes were observed 

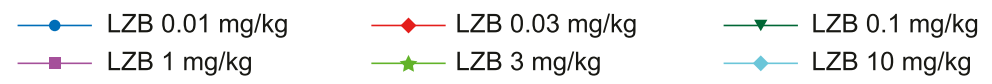

— LZB $0.3 \mathrm{mg} / \mathrm{kg}$

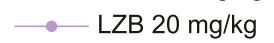

A (cohorts 1-8)
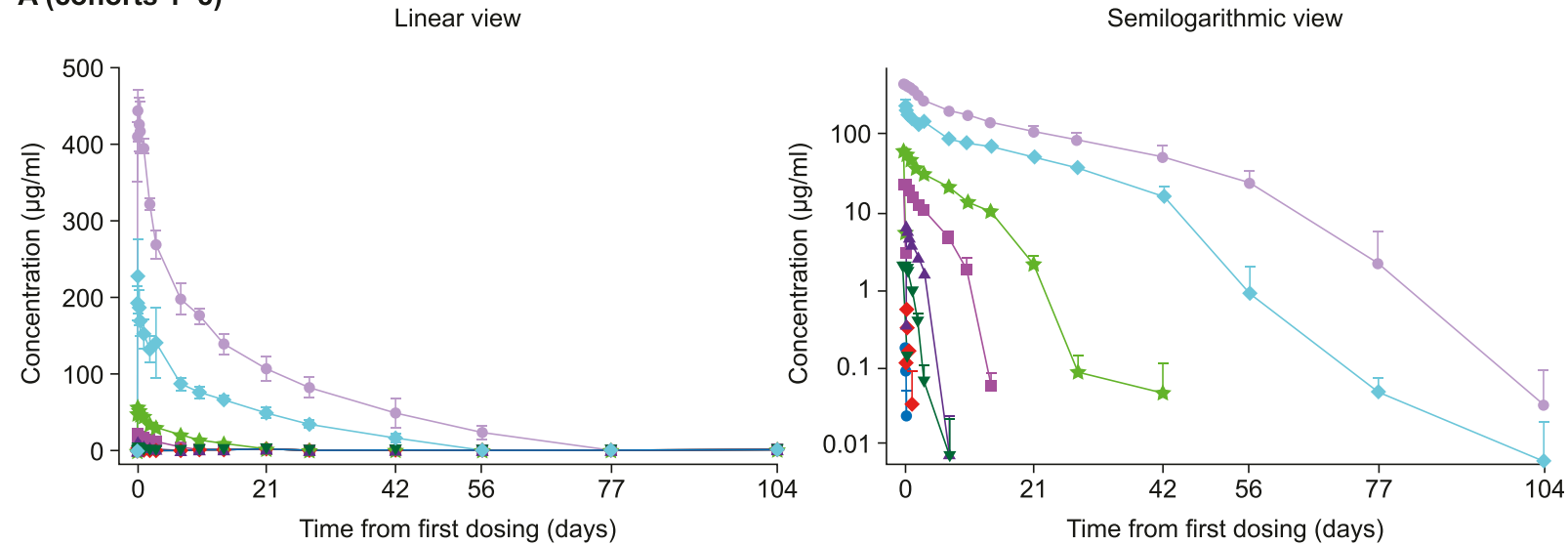

LZB $5 \mathrm{mg} / \mathrm{kg}$ q21d

Ł LZB $5 \mathrm{mg} / \mathrm{kg}$ q21d - only 1 dose

L LZB $10 \mathrm{mg} / \mathrm{kg}$ q56d - only 1 dose

B (cohorts 9 and 10)

Linear view

Semilogarithmic view
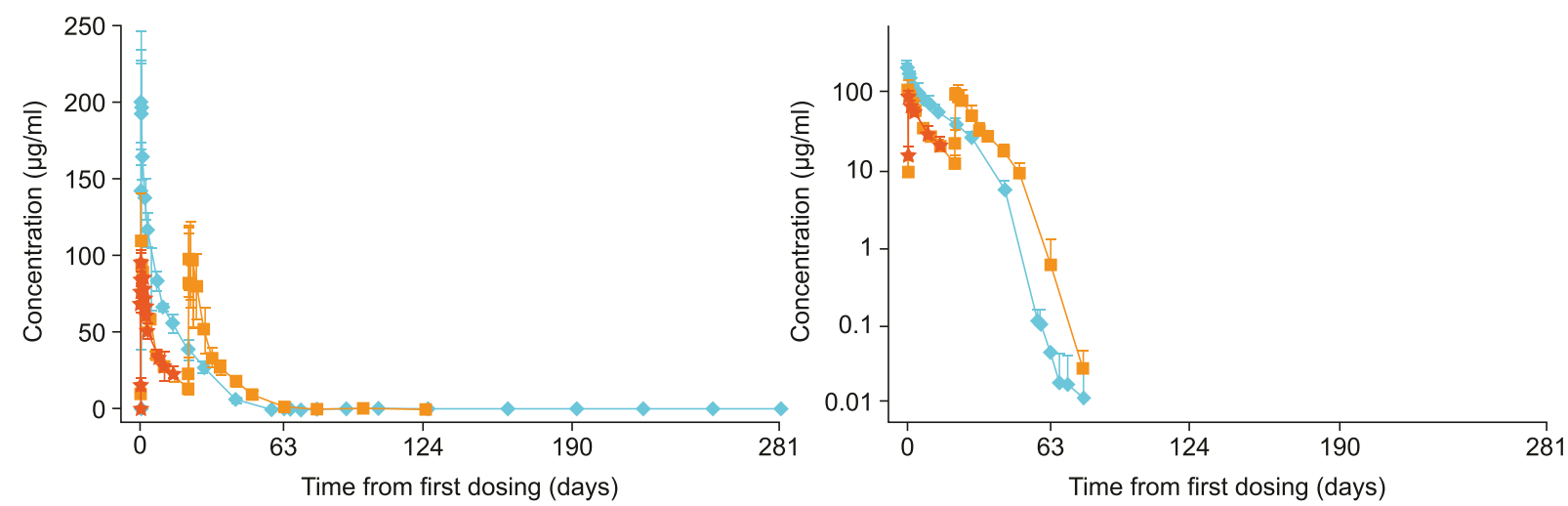

Fig. 2. Mean (S.D.) serum-free lacnotuzumab concentration versus time profiles by lacnotuzumab dose. LZB, lacnotuzumab; q21d, every 21 days; q56d, every 56 days; SD, standard deviation.

in serum soluble CSF-1R in individuals treated with lacnotuzumab compared with those who received placebo (Supplemental Fig. 3).

Compared with placebo, clear dose-dependent decreases from baseline in serum CTX-I were observed after single doses of lacnotuzumab ( $\geq 3 \mathrm{mg} / \mathrm{kg}$ ). CTX-I levels were suppressed from day 1 after lacnotuzumab administration, reaching maximal inhibition on day 22 , and remained suppressed by approximately $50 \%$ (for the $\geq 10 \mathrm{mg} / \mathrm{kg}$ dose) on day 105 , the last day of sampling (Supplemental Fig. 4). In contrast, no apparent dose-related changes in serum soluble TRAP5b were observed with lacnotuzumab (Supplemental Fig. 5). Although a $28.0 \%$ reduction from baseline was observed at day 105 in the $10 \mathrm{mg} / \mathrm{kg}$ dose groups, compared with placebo, this reduction was seen in only the higher dose groups and appeared to recover after day 105 in the repeat dose cohort.

There were no consistent dose-dependent effects of lacnotuzumab on circulating markers of bone formation. A single dose of lacnotuzumab induced a transient increase in PINP, bonespecific ALP, and osteocalcin (maximum GMR to baseline: $120.6 \%$ for PINP at day 8: $127.8 \%$ for bone-specific ALP at day 15 and $135.2 \%$ for osteocalcin at day 8 with the $10 \mathrm{mg} / \mathrm{kg}$ dose; Supplemental Figs. 6-8). By day 105, a single dose of lacnotuzumab, 10 or $20 \mathrm{mg} / \mathrm{kg}$, produced a decrease in PINP (GMR to baseline: $33.7 \%$ with the $10 \mathrm{mg} / \mathrm{kg}$ dose) and osteocalcin (GMR to baseline: $59.7 \%$ with the $10 \mathrm{mg} / \mathrm{kg}$ dose). Singledose treatment with lacnotuzumab produced a clear increase in levels of serum intact PTH (doses $\geq 1 \mathrm{mg} / \mathrm{kg}$ ) and serum OPG (doses $\geq 10 \mathrm{mg} / \mathrm{kg}$; Supplemental Figs. 9 and 10, respectively). Maximal increases in serum intact PTH and serum OPG both occurred at approximately day 29 (GMR to baseline: $171.6 \%$ and $157.5 \%$, respectively, for the $10 \mathrm{mg} / \mathrm{kg}$ dose), lasting up to day 57 . These increases were not associated with changes in serum calcium or phosphorus level or with changes in levels of biomarkers of calcium and phosphate homeostasis (25-hydroxyvitamin D and calcitonin; data not shown).

Compared with placebo, single doses of lacnotuzumab at $\geq 0.3 \mathrm{mg} / \mathrm{kg}$ resulted in clear dose-dependent decreases in total CD14+ and circulating CD14+CD16+ monocytes, with maximum reductions observed at approximately day 8 (Supplemental Fig. 11). Lacnotuzumab blockade of CSF-1 with doses $\leq 20 \mathrm{mg} / \mathrm{kg}$ had no effect on off-target leukocyte populations, including $\mathrm{T}$ lymphocytes (CD3+), helper T lymphocytes $(\mathrm{CD} 4+)$, cytotoxic T lymphocytes $(\mathrm{CD} 8+)$, B lymphocytes $(\mathrm{CD} 19+)$, natural killer cells $(\mathrm{CD} 16+$ and CD56+), and granulocytes. 


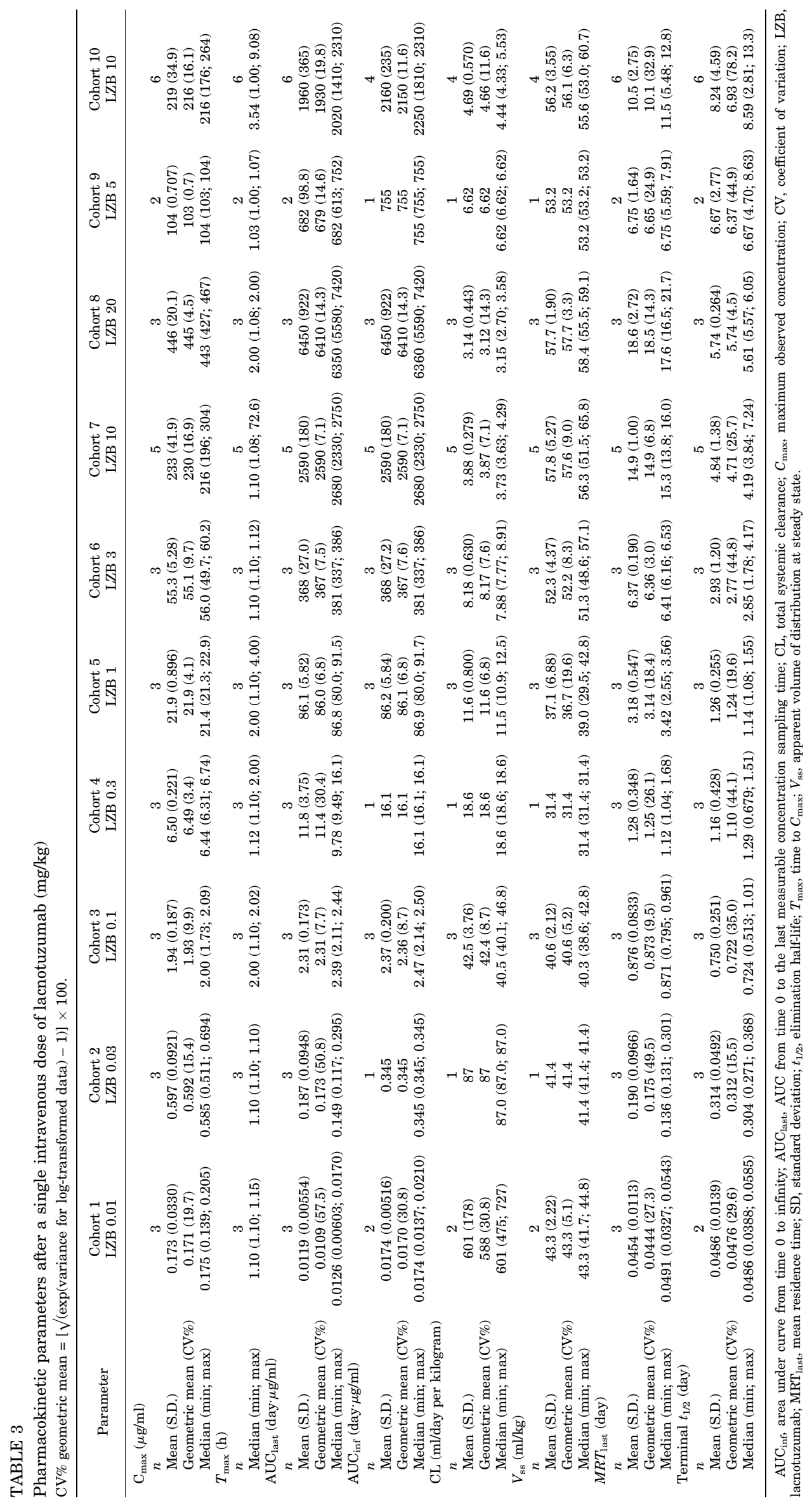


Serum CK

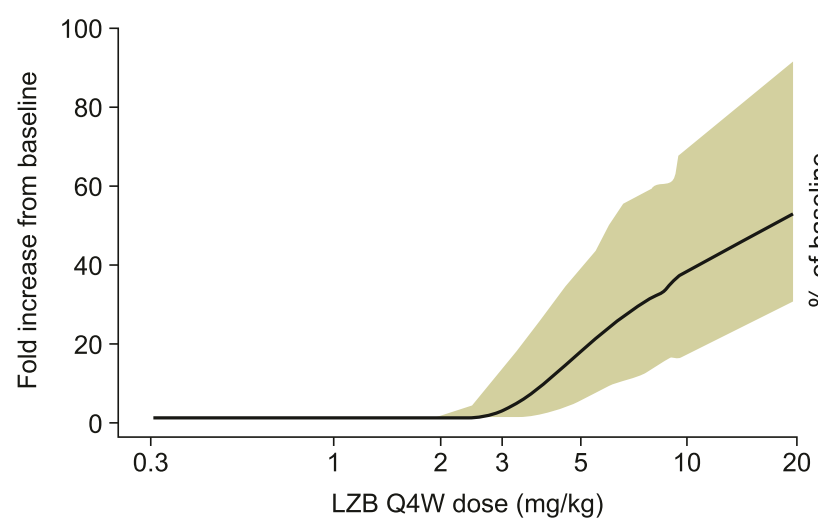

Circulating CD14+CD16+ cells

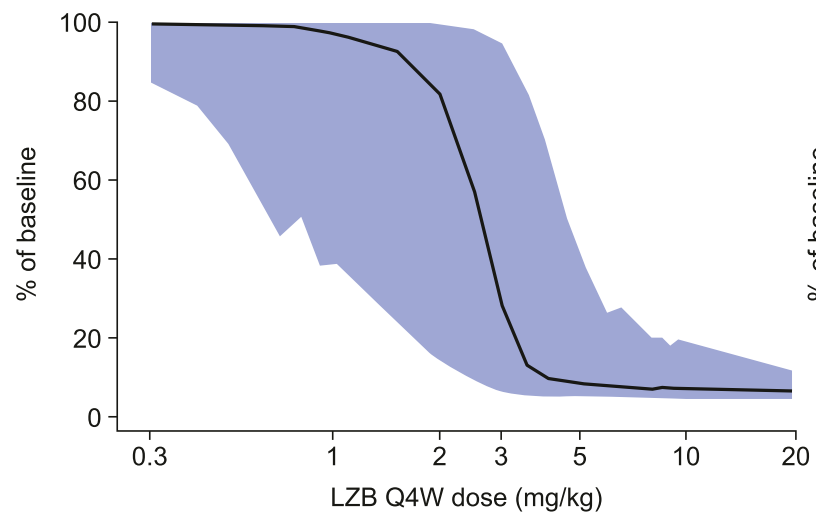

Serum CTX-I

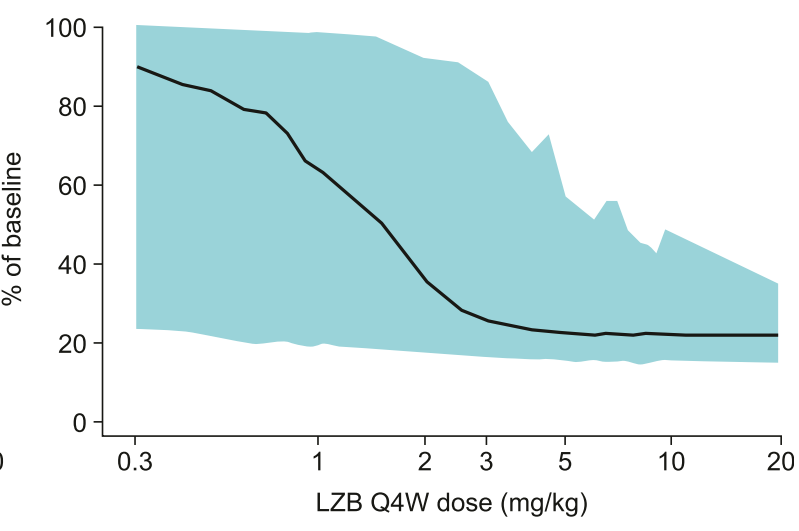

Circulating CD14+ cells

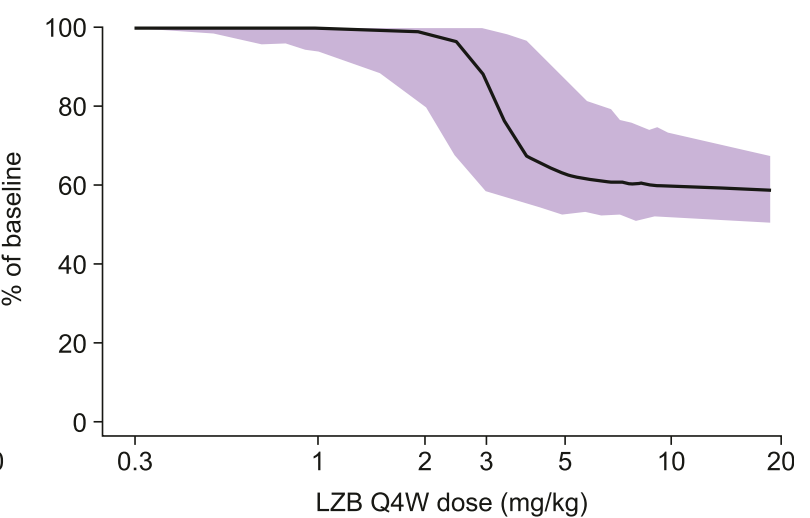

Fig. 3. Predicted steady-state dose-response relationships of lacnotuzumab for biomarkers of safety and efficacy. Black solid lines represent median predictions; shaded areas are 90\% prediction intervals (5\% and 95\% percentiles). CK, creatine kinase; CTX-I, collagen type 1 cross-linked C-telopeptide; LZB, lacnotuzumab; Q4W, every 4 weeks.

PK/PD Modeling. Free serum lacnotuzumab concentrationtime profiles were adequately described by a two-compartment disposition model with parallel linear and nonlinear elimination kinetics. For linear elimination, the model estimated a mean clearance of $0.2 \mathrm{l} /$ day, central volume of $3.8 \mathrm{l}$, intercompartmental clearance of $0.5 \mathrm{l} /$ day, and peripheral volume of $2.4 \mathrm{l}$. For nonlinear elimination, the maximum elimination rate was estimated at $5200 \mathrm{ng} / \mathrm{day}$ with a Michaelis-Menten constant of $490 \mathrm{ng} / \mathrm{ml}$ (Supplemental Table 3).

The effects of lacnotuzumab on the four biomarkers were modeled using indirect response models, which adequately described the longitudinal relationships between lacnotuzumab concentration and the biomarker responses for serum CTX-I, circulating CD14+CD16+ monocytes, circulating CD14+ monocytes, and serum CK. The established PK/PD models were used to simulate the steady-state dose-response relationships. Simulations suggested that the effect of lacnotuzumab on the four biomarkers was expected to be close to maximal at doses of $\geq 5 \mathrm{mg} / \mathrm{kg}$ every 4 weeks and minimal at doses of $\leq 1 \mathrm{mg} / \mathrm{kg}$ every 4 weeks (Fig. 3). Maximal median reduction in CTX-I at trough was predicted to be $80 \%$, but with high variability, and achievable with doses of $\geq 5 \mathrm{mg} / \mathrm{kg} \mathrm{Q} 4 \mathrm{~W}$. Full depletion of circulating CD14+CD16+ monocytes was predicted to occur with doses of $\geq 5 \mathrm{mg} / \mathrm{kg}$ every 4 weeks, whereas only a partial depletion of circulating CD14+ monocytes (a reduction of $40 \%$ ) was predicted, with maximal effects at doses of $\geq 5 \mathrm{mg} / \mathrm{kg}$ every 4 weeks. Trough serum CK was predicted to increase with doses $\geq 3 \mathrm{mg} / \mathrm{kg}$. With lacnotuzumab $10 \mathrm{mg} / \mathrm{kg}$ every 4 weeks, trough serum CK was estimated to be approximately 40 times higher than at baseline, and 20 times higher than at baseline with the $5 \mathrm{mg} / \mathrm{kg}$ every 4 weeks dose.

AEs. The total number of reported AEs was 123, reported in 39 participants; most of the AEs were mild (grade 1, $n=85$; grade 2, $n=21$; grade $3, n=11$; grade $4, n=6$ ). Of the 36 individuals randomized in part A, $26(72.2 \%)$ experienced $\geq 1 \mathrm{AE}$ (Table 4). The most commonly affected system organ classes were infections and infestations, nervous system disorders, and skin and subcutaneous tissue disorders (all $n$ $=8,22.2 \%)$. The most frequent AEs were raised blood CK $(n=$ $6,16.7 \%$ ) and headache and ecchymosis (each $n=4,11.1 \%$ ); one vasovagal syncopal episode (grade 3 ) occurred in the placebo group, and diastolic hypertension (grade 3 ) occurred in one subject treated with lacnotuzumab $0.1 \mathrm{mg} / \mathrm{kg}$.

In part B, six (75.0\%) of the eight participants in cohort 9 and seven $(87.5 \%)$ of the eight in cohort 10 reported $\geq 1 \mathrm{AE}$ (Table 5). In both cohorts, the most commonly affected system organ class was investigations (cohort $9, n=4,50.0 \%$; cohort $10, n=6,75.0 \%$ ). The most frequent AEs were raised blood CK (cohort 9, $n=4,50.0 \%$; cohort 10, $n=6,75.0 \%$ ) and periorbital swelling (cohort 10, $n=4,50.0 \%$ ). No individual discontinued the study because of AEs, and no deaths occurred. One serious $\mathrm{AE}$ of compartment syndrome was reported in one individual in cohort 9 (Table 5), although this occurred after the end of the 


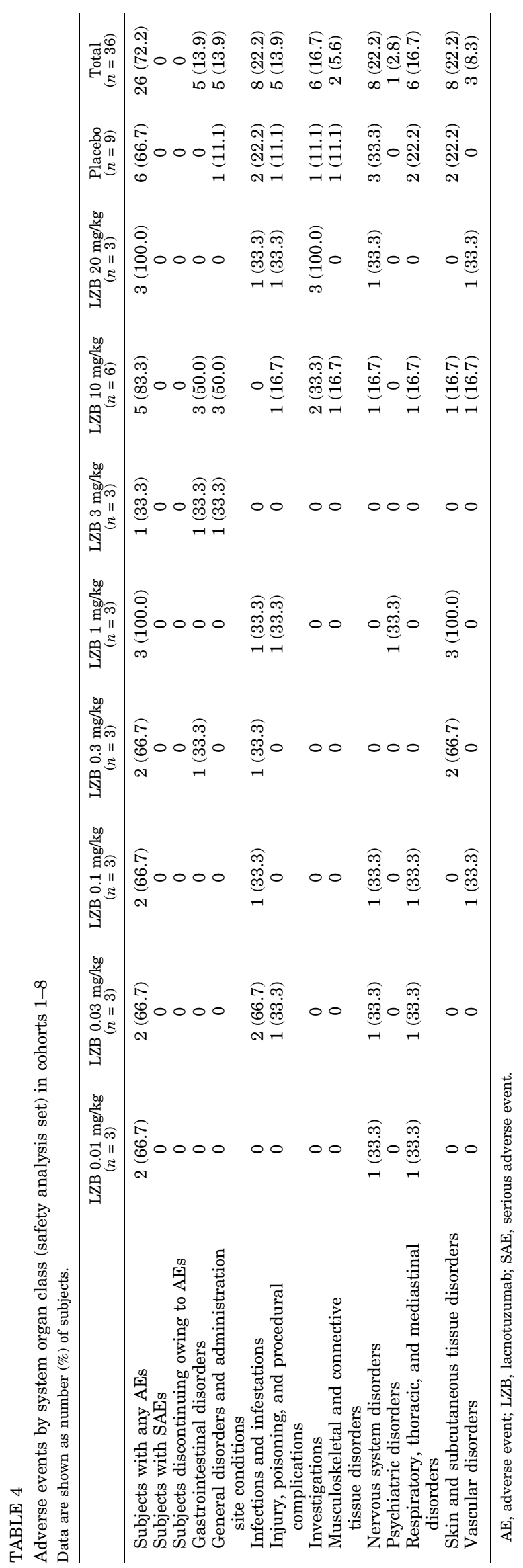

study and was not suspected to be related to the study drug. The occurrence of raised blood CK and periorbital swelling was consistent with the profile of a CSF-1 pathway antagonist.

Immunogenicity. Of the 39 individuals who received $\geq 1$ dose of lacnotuzumab, antidrug antibody (ADA) signals were detected predose (at screening or at day -3) and at similar titers in postdose samples in three individuals (range, 49.2-393.0). Postdose titers were within the naturally expressed variation (95\% confidence interval) of those detected predose and thus were not indicative of treatmentdriven ADAs. A single individual developed de novo ADAs (cohort 8, $20 \mathrm{mg} / \mathrm{kg}$, detected on day 106) that were considered possibly related to treatment. However, the titer was within the range of ADAs seen predose, and the presence of ADAs in this individual did not appear to affect the PK/PD parameters of lacnotuzumab when compared with the rest of the cohort. In the placebo groups $(n=13), \mathrm{ADA}$ signals were detected predose and up to postdose day 106 in one individual, with a natural variation of $39 \%$ between samples.

Nonclinical Mechanistic Investigation of CK Elevation and Periorbital Swelling. A significant decrease in His-tagged CK-M clearance occurred after lacnotuzumab administration compared with before lacnotuzumab administration. $C_{\max }$ values and volume of distribution at steady state for CK were similar before and after lacnotuzumab treatment; however, after lacnotuzumab treatment, significant increases were seen in His-tagged CK-M area under the curve and plasma half-life (approximately 5-fold and 3-fold higher, respectively). The predicted clearance rate after lacnotuzumab treatment was about $20 \%$ of the rate observed before treatment (Fig. 4), and the calculated half-life after lacnotuzumab administration was approximately 3-fold greater than before treatment. Levels of miR-1, miR-122, miR-206, miR-486-5p, and miR-486-3p showed no change after treatment with lacnotuzumab (Supplemental Fig. 12), suggesting that there was no evidence of liver, heart, or skeletal muscle injury.

During the 26-week toxicity study of once-weekly lacnotuzumab, periorbital swelling was observed, starting on day 29 of the dosing phase in all animals receiving 20 or $100 \mathrm{mg} / \mathrm{kg}$. In histology, periorbital swelling correlated with accumulations of basophilic material in the subcutis and dermis of the eyelid and eye bag. Upon histochemical special staining, the basophilic accumulations were positive for Alcian blue $\mathrm{pH} 2.5$, and negative for Alcian blue $\mathrm{pH} 0.5$ and for PAS, and were identified as an accumulation of acidic nonsulfated glycosaminoglycans that were mainly composed of hyaluronic acid (Hodson and Prout, 1968; Smoller and Hiatt, 2009; Frantz et al., 2010) (Fig. 5). In all animals that entered the 38-week recovery period, periorbital swelling had fully recovered by day 438 , indicating that the accumulations of basophilic material were fully reversible and were cleared once CSF-1 levels returned close to baseline levels. Accumulation of basophilic material was noted not only in the eyelid and eye bag but also in numerous other organs; this accumulation was generally associated with pre-existing collagenous connective tissue and was reversible.

\section{Discussion}

Single dosing of lacnotuzumab up to $10 \mathrm{mg} / \mathrm{kg}$ demonstrated a good safety and tolerability profile, with no discontinuations owing to AEs. In part A, all participants receiving lacnotuzumab 
TABLE 5

Adverse events by system organ class (safety analysis set) in cohorts 9 and 10 Data are shown as number $(\%)$ of subjects.

\begin{tabular}{|c|c|c|c|c|c|c|}
\hline & $\underset{(n=6)}{\text { LZB } 5 \mathrm{mg} / \mathrm{kg} \text { q21d }}$ & $\begin{array}{l}\text { Placebo } \\
(n=2)\end{array}$ & $\begin{array}{c}\text { Total } \\
(n=8)\end{array}$ & $\begin{array}{c}\text { LZB } 10 \mathrm{mg} / \mathrm{kg} \text { q } 56 \mathrm{~d} \\
(n=6)\end{array}$ & $\begin{array}{l}\text { Placebo } \\
(n=2)\end{array}$ & $\begin{array}{c}\text { Total } \\
(n=8)\end{array}$ \\
\hline Subjects with AEs & $5(83.3)$ & $1(50.0)$ & $6(75.0)$ & $6(100.0)$ & $1(50.0)$ & $7(87.5)$ \\
\hline Subjects with SAEs & $1(16.7)$ & 0 & $1(12.5)^{a}$ & 0 & 0 & 0 \\
\hline Subjects discontinuing owing to AEs & 0 & 0 & 0 & 0 & 0 & 0 \\
\hline Eye disorders & 0 & 0 & 0 & $4(66.7)$ & $1(50.0)$ & $5(62.5)$ \\
\hline Gastrointestinal disorders & 0 & 0 & 0 & $2(33.3)$ & 0 & $2(25.0)$ \\
\hline General disorders and administration site conditions & 0 & 0 & 0 & $2(33.3)$ & $1(50.0)$ & $3(37.5)$ \\
\hline Infections and infestations & 0 & $1(50.0)$ & $1(12.5)$ & $2(33.3)$ & 0 & $2(25.0)$ \\
\hline Injury, poisoning, and procedural complications & $2(33.3)$ & 0 & $2(25.0)$ & $2(33.3)$ & 0 & $2(25.0)$ \\
\hline Investigations & $4(66.7)$ & 0 & $4(50.0)$ & $6(100.0)$ & 0 & $6(75.0)$ \\
\hline Musculoskeletal and connective tissue disorders & $1(16.7)$ & 0 & $1(12.5)$ & $2(33.3)$ & 0 & $2(25.0)$ \\
\hline Nervous system disorders & $1(16.7)$ & 0 & $1(12.5)$ & $3(50.0)$ & $1(50.0)$ & $4(50.0)$ \\
\hline Respiratory, thoracic, and mediastinal disorders & 0 & 0 & 0 & $3(50.0)$ & 0 & $3(37.5)$ \\
\hline Skin and subcutaneous tissue disorders & 0 & 0 & 0 & $2(33.3)$ & 0 & $2(25.0)$ \\
\hline Social circumstances & 0 & 0 & 0 & $1(16.7)$ & 0 & $1(12.5)$ \\
\hline
\end{tabular}

AE, adverse event; LZB, lacnotuzumab; q21d, every 21 days; q56d, every 56 days; SAE, serious adverse event.

${ }^{a}$ The SAEs reported here occurred after the end of the study and was not suspected to be related to study drug.

at doses $>1 \mathrm{mg} / \mathrm{kg}$ completed the study as planned, ensuring that the MTD was established correctly. No unexpected or novel AEs were observed, and there was no effect on vital signs or ECG. AEs were generally mild, except for one vasovagal syncopal episode with placebo, diastolic hypertension in one individual receiving lacnotuzumab $0.1 \mathrm{mg} / \mathrm{kg}$, and compartment syndrome in one individual after the study end, which was not considered related to study drug. At higher doses (10 and $20 \mathrm{mg} / \mathrm{kg}$ ), however, CK elevations $>5 \times$ ULN and mild periorbital swelling were reported. Data on the effect of multiple dosing on the lacnotuzumab $\mathrm{AE}$ profile are limited; only four patients received two doses of lacnotuzumab ( $5 \mathrm{mg} / \mathrm{kg}$; all in cohort 9). Although the AE profile did not alter after the second dose of lacnotuzumab, no inferences can be made regarding the safety profile of multiple dosing.

All CK elevations were asymptomatic, reversible, and not associated with muscle tissue damage, as evidenced by a lack of increase in levels of cardiac troponin $\mathrm{T}$ (a marker for cardiac muscle infarct) and aldolase (a marker for skeletal muscle tissue damage). Considering our data from nonhuman primates, it is likely that the elevations were caused by the pharmacologic effects of lacnotuzumab in reducing the number of liver-resident macrophages (Kupffer cells), which are involved in the normal elimination plasma enzymes, including CK (Bijsterbosch et al., 1983; Horiuchi et al., 1985; Kamimoto et al., 1985; Smit et al., 1986, 1987, 1988).

The mechanistic investigation in cynomolgus monkeys demonstrated that CK increases were caused by the lacnotuzumab-induced reduction in CK clearance, with no evidence of tissue injury. Similar effects have been observed in a separate study of antibody-mediated CSF-1 inhibition in cynomolgus monkeys (Radi et al., 2011). CK elevations may thus be considered an expected pharmacologic effect of lacnotuzumab and not an AE. In clinical practice, however, CK elevations might obscure a concomitant cardiac event, which would be mitigated by testing troponin along with CK. Distinguishing between elevated serum levels of CK attributable to its reduced clearance compared with elevations resulting from liver or muscle injury is difficult for clinicians, and the possibility of clearance changes should be considered in future studies of CSF-1/CSF-1R antagonists.

Decreased serum protein clearance of CK after lacnotuzumab treatment owing to reductions in tissue macrophages may also occur in humans; it has been demonstrated in humans that blocking CSF-1R depletes resident macrophages (Ries et al., 2014). This depletion is also likely responsible for the transient increase in AST, which is normally eliminated via Kupffer cells, as shown in a preclinical investigation of the CSF-1R antagonist BLZ945 (Wang et al., 2011), suggesting that this mechanism leading to artifactual AEs of increased biomarker enzymes may be common to agents targeting the CSF-1 pathway.

Occurrences of periorbital swelling were mild and transient (duration: 2-158 days), and no individuals experiencing periorbital swelling had developed ADAs, ruling out antibody development as a cause. The investigation of periorbital swelling in cynomolgus monkeys demonstrated that these events were not true edema but were caused by the reversible accumulation of hyaluronan-rich extracellular matrix in collagenous connective tissue. Like the clearance of circulating enzymes, extracellular matrix is maintained by macrophages (Verma and Hansch, 2007; Best et al., 2016) and so may be a mild and transient on-target effect of lacnotuzumab.

The PK of free lacnotuzumab in serum was nonlinear across doses of $0.01-20 \mathrm{mg} / \mathrm{kg}$, with faster apparent elimination at lower doses or concentrations. This phenomenon was considered primarily due to apparent TMDD, as the PK assay measured free drug, not bound to CSF-1. At lower doses or concentrations, the apparent more rapid decline in free lacnotuzumab concentration was considered caused by circulating lacnotuzumab having bound to its target, making it no longer detectable in the assay. At higher doses or concentrations, the amount of circulating lacnotuzumab far exceeded that needed to saturate its target, resulting in typical IgG1 PK profiles (slow elimination and long residence time). This hypothesis was supported by the significant increase in plasma total CSF-1 after lacnotuzumab treatment. We believe this was due to the slower clearance of the lacnotuzumab-CSF-1 immunocomplex, indicating successful target engagement.

Indeed, the increase in plasma total CSF-1 was lacnotuzumab dose-dependent, in that the greater the lacnotuzumab dose or free lacnotuzumab available for target binding, the greater the increase in total CSF-1. This increase plateaued at doses of 10 and $20 \mathrm{mg} / \mathrm{kg}$, suggesting the target was saturated at these concentrations. The possibility of homeostatic upregulation of CSF-1 after lacnotuzumab administration was 
A

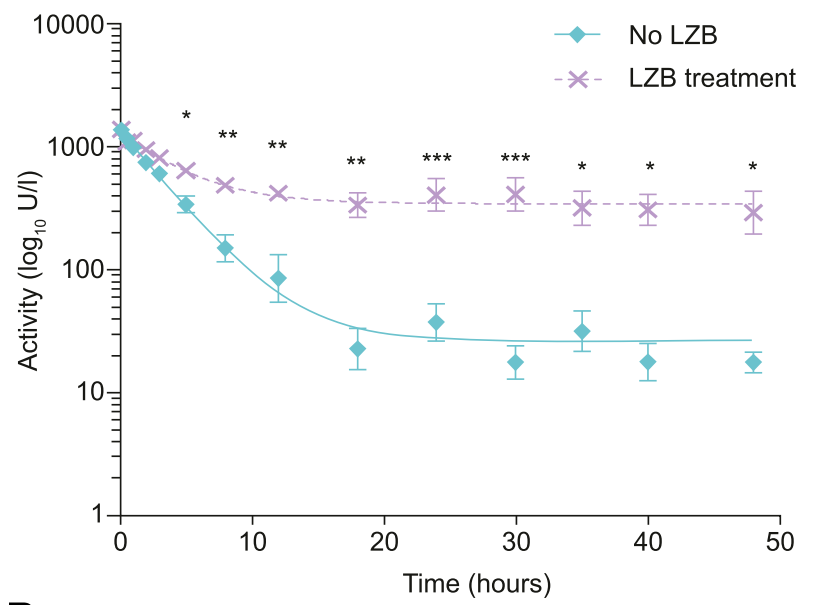

B

\begin{tabular}{lccccc}
\hline $\begin{array}{l}\text { Treatment } \\
\text { phase }\end{array}$ & & $\begin{array}{c}\mathbf{V} \\
(\mathbf{I} / \mathbf{k g})\end{array}$ & $\begin{array}{c}\mathbf{V 2} \\
(\mathbf{I} / \mathbf{k g})\end{array}$ & $\begin{array}{c}\mathbf{C l} \\
(\mathbf{I} / \mathbf{h} / \mathbf{k g})\end{array}$ & $\begin{array}{c}\mathbf{C l 2} \\
(\mathbf{I} / \mathbf{h} / \mathbf{k g})\end{array}$ \\
\hline No LZB & Estimate & 0.3231 & 0.5867 & 0.0644 & 0.0284 \\
& SEM & 0.0264 & 0.0354 & 0.0040 & 0.0068 \\
\cline { 2 - 6 } & $\mathrm{CV} \%$ & 8.16 & 6.03 & 6.21 & 24.01 \\
& $2.5 \%$ & 0.2704 & 0.5159 & 0.0564 & 0.0148 \\
& $97.5 \%$ & 0.3758 & 0.6574 & 0.0724 & 0.0420 \\
\hline LZB & Estimate & 0.2819 & 0.3305 & 0.0016 & 0.0705 \\
treatment & SEM & 0.0119 & 0.0669 & 0.0005 & 0.0192 \\
\cline { 2 - 6 } & CV\% & 4.22 & 20.25 & 29.53 & 27.23 \\
& $2.5 \%$ & 0.2581 & 0.1967 & 0.0006 & 0.0321 \\
& $97.5 \%$ & 0.3057 & 0.4643 & 0.0025 & 0.1089 \\
\hline
\end{tabular}

Fig. 4. His-CK activity and population pharmacokinetic parameters of His-CK before and after lacnotuzumab treatment. Animals were first injected with His-CK, and clearance was measured without lacnotuzumab [no LZB]; the same animals were thereafter dosed with lacnotuzumab and then injected with His-CK before measuring clearance anew (LZB treatment). (A) Plasma His-CK activities before and after LZB treatment (mean \pm S.E.M.), determined 48 hours after His-CK injection. Statistics: Repeated-measures two-way analysis of variance with post hoc Sidak multiple comparison test $(\alpha=0.05) ; *^{P}<0.05 ; * * P<0.01 ; * * * P<0.001$ versus timepoint-matched pretest value. (B) Population pharmacokinetic parameters of injected His-CK using a two-compartment pharmacokinetic model. His-CK, histidine-tagged creatine kinase; $\mathrm{Cl}$, elimination clearance; $\mathrm{Cl} 2$, intercompartment clearance; CV, coefficient of variation; LZB, lacnotuzumab; SEM, standard error of the mean; $\mathrm{V}$, volume of central compartment; V2, volume of peripheral compartment.

investigated via an extended follow-up period in part B. Data up to 280 days postdose were available for one participant, who experienced a decline in plasma total CSF-1 concentrations toward baseline levels, indicating no upregulation of CSF-1 post-treatment.

We noted significant dose-dependent and on-target effects of lacnotuzumab on multiple downstream biomarkers, strongly indicating successful target and pathway engagement across a wide range of doses and target tissues. These included dose-dependent reductions in circulating CD14+CD16+ monocytes (a monocyte subpopulation with a phenotype resembling that of tissue macrophages) and CTX-I, a marker of bone resorption (reflecting the number and function of osteoclasts). The decrease in CTX-I could be explained by a decrease in the number and/or activity of osteoclasts; however, lacnotuzumab had no effect on soluble TRAP5b, another marker of osteoclast activity and bone resorption. This discrepancy might be explained by TRAP5b being a weaker marker of osteoclast activity than CTX-I (Wheater et al., 2013). Alternatively, the effect of lacnotuzumab on CSF-1 may result in a reduction of newly formed osteoclasts without affecting the activity of mature osteoclasts. Lacnotuzumab had no consistent or dose-dependent effect on the levels of circulating bone remodeling markers, N-MID osteocalcin, PINP, and BSAP. Lacnotuzumab treatment did show a clear increase in the levels of bone homeostasis markers (intact PTH and osteoprotegerin), which did not affect calcium and phosphate homeostasis.

Only one individual developed de novo lacnotuzumab ADAs, but the presence of low-titer ADAs cannot be ruled out for other individuals. Many samples contained high concentrations of lacnotuzumab that may have interfered with the assay. Regardless, any potentially undetected ADAs had no apparent impact on the lacnotuzumab PK/PD profiles. An additional limitation of this study includes the low number of patients with longer-term follow-up in cohorts 9 and 10. It should also be recognized that the mechanistic interpretations of the CK elevation and periorbital swelling seen in patients are extrapolated from animal studies.

Similar preliminary phase 1 or phase 2 studies examining the effects of other inhibitors of the CSF-1/CSF-1R pathway have yielded mixed results. A phase 2a study of JNJ-40346527 (a selective CSF-1R kinase inhibitor) in patients with active RA despite disease-modifying antirheumatic drug therapy $(n=95)$ demonstrated target engagement of the inhibitor but no difference in efficacy versus placebo (Genovese et al., 2015). Likewise, a phase 1b study of PD-0360324 (a human IgG2 monoclonal antibody that inhibits CSF-1 binding to CSF-1R) in patients with cutaneous lupus erythematosus $(n=28)$ demonstrated target engagement, but no therapeutic effects were observed (Masek-Hammerman et al., 2016). The most promising effects of CSF-1/CSF-1R inhibition have been reported in patients with PVNS, with several studies demonstrating clear therapeutic benefits (i.e., tumor volume regression, objective response, complete response, and symptomatic improvement) (Cassier et al., 2012, 2015; Stacchiotti et al., 2013; Tap et al., 2015).

Taken together, these data provide support and justification for the further evaluation of lacnotuzumab in future studies in patients who have PVNS, and in other diseases in which the CSF-1/CSF-1R signaling pathway is implicated. Data from this study will be used to evaluate the benefit-risk profile of single- and multiple-dose lacnotuzumab regimens, while results from the PD studies and the dose-exposure-response modeling will help inform dose and regimen selection for subsequent proof-of-concept and phase 2 clinical studies.

This study in healthy volunteers showed that lacnotuzumab, a monoclonal antibody against CSF-1, was generally well tolerated at doses $\leq 10 \mathrm{mg} / \mathrm{kg}$. The combination of clinical and preclinical studies presented here demonstrate that CK elevation and periorbital swelling are unlikely to be related to organ injury or toxicity, but rather reflect pharmacologic inhibition of macrophage-mediated clearance of molecules in the liver and skin.

The PK of free lacnotuzumab in serum was nonlinear across the dose range, with faster apparent elimination observed at lower doses or concentrations, and was consistent with the apparent TMDD of lacnotuzumab. At higher doses or concentrations, lacnotuzumab showed typical IgG1 PK profiles, with slow apparent elimination and a long residence time. 


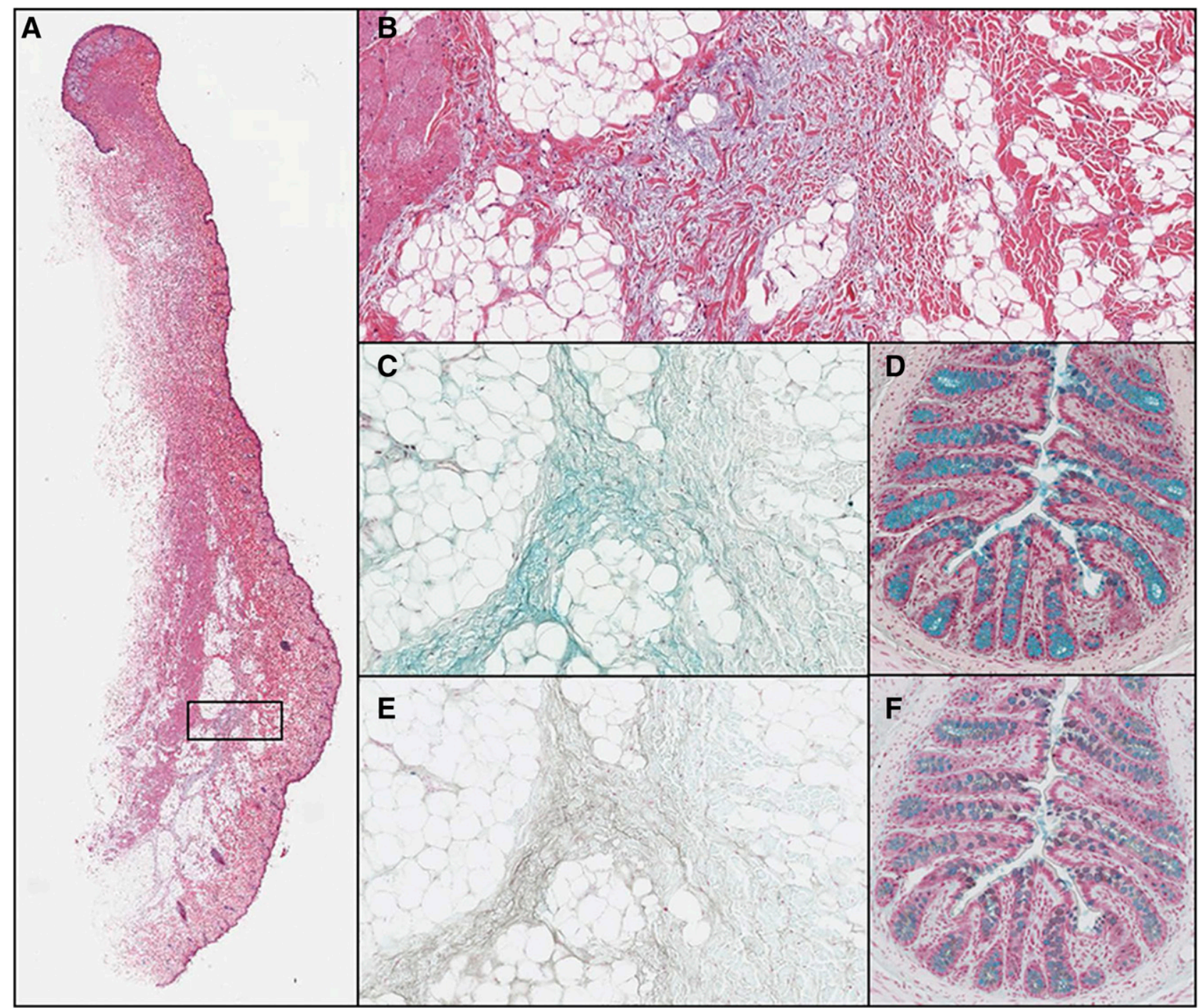

Fig. 5. Histochemical special stainings and investigation of the periorbital swelling observed with lacnotuzumab. (A) hematoxylin and eosin-stained tissue section of the eyelid and eye bag of an animal dosed with $100 \mathrm{mg} / \mathrm{kg}$ lacnotuzumab showing accumulation of basophilic material in the dermis and subcutis. (B) Higher magnification of the outlined area. (C) Alcian $\mathrm{pH} 2.5$ staining, with the corresponding positive control in (D). (E) Alcian pH 0.5 staining. (F) Corresponding positive control. Periodic acid-Schiff stainings are not shown.

Furthermore, lacnotuzumab demonstrated significant dosedependent and on-target PD effects on multiple downstream biomarkers, including clear reductions in circulating CD14+ CD16+ monocytes and CTX-I, a marker of bone resorption. Dose-exposure-response modeling suggested that the effect of lacnotuzumab on the efficacy biomarkers is maximized at doses $\geq 5 \mathrm{mg} / \mathrm{kg}$ every 4 weeks. Together, these data support the further evaluation of lacnotuzumab in patients with PVNS and in other diseases involving abnormalities in the CSF-1/CSF-1R signaling pathway.

\section{Acknowledgments}

We thank Dr. Ian M. Williams, Oxford PharmaGenesis Ltd (Oxford, UK), for professional writing support.

\section{Authorship Contributions}

Participated in research design: Pognan, Couttet, Demin, Jaitner, Pang, Roubenoff, Sutter, Timsit, Valentin, Vogel, Woerly, Wolf, Schramm.
Performed data analysis: Pognan, Couttet, Demin, Jaitner, Pang, Sutter, Timsit, Valentin, Vogel, Woerly, Wolf, Schramm.

Wrote or contributed to the writing of the manuscript: Pognan, Couttet, Demin, Jaitner, Pang, Roubenoff, Sutter, Timsit, Valentin, Vogel, Woerly, Wolf, Schramm.

\section{References}

Achkova D and Maher J (2016) Role of the colony-stimulating factor (CSF)/CSF-1 receptor axis in cancer. Biochem Soc Trans 44:333-341.

Best J, Verhulst S, Syn WK, Lagaisse K, van Hul N, Heindryckx F, Sowa JP, Peeters L, Van Vlierberghe H, Leclercq IA, et al. (2016) Macrophage depletion attenuates extracellular matrix deposition and ductular reaction in a mouse model of chronic cholangiopathies. PLoS One 11:e0162286.

Bijsterbosch MK, Duursma AM, Bouma JM, and Gruber M (1983) Plasma clearance and endocytosis of cytosolic malate dehydrogenase in the rat. Biochem $J$ 210: 419-428.

Brahmi M, Vinceneux A, and Cassier PA (2016) Current systemic treatment options for tenosynovial giant cell tumor/pigmented villonodular synovitis: targeting the CSF1/CSF1R axis. Curr Treat Options Oncol 17:10.

Calvo A, Joensuu H, Sebastian M, Naing A, Bang Y-J, Martin M, Roda D, Hodi FS, Veloso A, Mataraza J, et al. (2018) Phase Ib/II study of lacnotuzumab (MCS110) combined with spartalizumab (PDR001) in patients (pts) with advanced tumors (Abstract). J Clin Oncol 36:3014.

Campion S, Aubrecht J, Boekelheide K, Brewster DW, Vaidya VS, Anderson L, Burt D, Dere E, Hwang K, Pacheco S, et al. (2013) The current status of biomarkers for predicting toxicity. Expert Opin Drug Metab Toxicol 9:1391-1408. 
Cannarile MA, Weisser M, Jacob W, Jegg AM, Ries CH, and Rüttinger D (2017) Colony-stimulating factor 1 receptor (CSF1R) inhibitors in cancer therapy. $J$ Immunother Cancer 5:53.

Cassier PA, Gelderblom H, Stacchiotti S, Thomas D, Maki RG, Kroep JR, van der Graaf WT, Italiano A, Seddon B, Dômont J, et al. (2012) Efficacy of imatinib mesylate for the treatment of locally advanced and/or metastatic tenosynovial giant cell tumor/pigmented villonodular synovitis. Cancer 118:1649-1655.

Cassier PA, Italiano A, Gomez-Roca CA, Le Tourneau C, Toulmonde M, Cannarile MA, Ries C, Brillouet A, Müller C, Jegg AM, et al. (2015) CSF1R inhibition with emactuzumab in locally advanced diffuse-type tenosynovial giant cell tumours of the soft tissue: a dose-escalation and dose-expansion phase 1 study. Lancet Oncol 16:949-956.

Cupp JS, Miller MA, Montgomery KD, Nielsen TO, O'Connell JX, Huntsman D, van de Rijn M, Gilks CB, and West RB (2007) Translocation and expression of CSF1 in pigmented villonodular synovitis, tenosynovial giant cell tumor, rheumatoid arthritis and other reactive synovitides. Am J Surg Pathol 31:970-976.

Dillberger JE, Monroy P, and Altman NH (1987) Delayed increase in plasma lactic dehydrogenase activity in mouse hepatitis virus-infected mice subsequently infected with lactic dehydrogenase virus. Lab Anim Sci 37:792-794.

Dwyer AR, Greenland EL, and Pixley FJ (2017) Promotion of tumor invasion by tumor-associated macrophages: the role of CSF-1-activated phosphatidylinositol 3 kinase and Src family kinase motility signaling. Cancers (Basel) $\mathbf{9}$

Fixe P and Praloran V (1997) Macrophage colony-stimulating-factor (M-CSF or CSF-1) and its receptor: structure-function relationships. Eur Cytokine Netw 8:125-136.

Frantz C, Stewart KM, and Weaver VM (2010) The extracellular matrix at a glance. $J$ Cell Sci 123:4195-4200.

Garcia S, Hartkamp LM, Malvar-Fernandez B, van Es IE, Lin H, Wong J, Long L, Zanghi JA, Rankin AL, Masteller EL, et al. (2016) Colony-stimulating factor (CSF) 1 receptor blockade reduces inflammation in human and murine models of rheumatoid arthritis. Arthritis Res Ther 18:75.

Genovese MC, Hsia E, Belkowski SM, Chien C, Masterson T, Thurmond RL, Manthey CL, Yan XD, Ge T, Franks C, et al. (2015) Results from a phase IIA parallel group study of JNJ-40346527, an oral CSF-1R inhibitor, in patients with active rheumatoid arthritis despite disease-modifying antirheumatic drug therapy. $J$ Rheumatol 42:1752-1760.

Hayashi T, Salata K, Kingman A, and Notkins AL (1988) Regulation of enzyme levels in the blood. Influence of environmental and genetic factors on enzyme clearance. Am J Pathol 132:503-511.

Hodson JJ and Prout RE (1968) Chemical and histochemical characterization of mucopolysaccharides in a jaw myxoma. J Clin Pathol 21:582-589.

Horiuchi S, Kamimoto Y, and Morino Y (1985) Hepatic clearance of rat liver aspartate aminotransferase isozymes: evidence for endocytotic uptake via different binding sites on sinusoidal liver cells. Hepatology 5:376-382.

Kamimoto Y, Horiuchi S, Tanase S, and Morino Y (1985) Plasma clearance of intravenously injected aspartate aminotransferase isozymes: evidence for preferential uptake by sinusoidal liver cells. Hepatology 5:367-375.

Masek-Hammerman K, Peeva E, Ahmad A, Menon S, Afsharvand M, Peng Qu R, Cheng JB, Syed J, Zhan Y, O'Neil SP, et al. (2016) Monoclonal antibody against macrophage colony-stimulating factor suppresses circulating monocytes and tissue macrophage function but does not alter cell infiltration/activation in cutaneous lesions or clinical outcomes in patients with cutaneous lupus erythematosus. Clin Exp Immunol 183:258-270.

Menke J, Hsu MY, Byrne KT, Lucas JA, Rabacal WA, Croker BP, Zong XH, Stanley ER, and Kelley VR (2008) Sunlight triggers cutaneous lupus through a CSF-1dependent mechanism in MRL-Fas(lpr) mice. J Immunol 181:7367-7379.

Menke J, Rabacal WA, Byrne KT, Iwata Y, Schwartz MM, Stanley ER, Schwarting A and Kelley VR (2009) Circulating CSF-1 promotes monocyte and macrophage phenotypes that enhance lupus nephritis. J Am Soc Nephrol 20:2581-2592.

Nieto JC, Zamora C, Cantó E, Garcia-Planella E, Gordillo J, Ortiz MA, Juárez C, and Vidal S (2017) CSF-1 regulates the function of monocytes in Crohn's disease patients in remission. Sci Rep 7:92.
Pixley FJ and Stanley ER (2004) CSF-1 regulation of the wandering macrophage: complexity in action. Trends Cell Biol 14:628-638.

Pryer N, Sung V, Jeffry U, Peng J, Oei Y, Cao Y, Horwitz A, Meyer K, Price J, Liu C, et al. (2009) Abstract \#DDT02-2: MCS110: a monoclonal antibody with potent neutralizing activity against macrophage colony-stimulating factor for the treatment of tumor-induced osteolysis. Cancer Res 69:DDT02.

Pyonteck SM, Akkari L, Schuhmacher AJ, Bowman RL, Sevenich L, Quail DF, Olson OC, Quick ML, Huse JT, Teijeiro V, et al. (2013) CSF-1R inhibition alters macrophage polarization and blocks glioma progression. Nat Med 19:1264-1272.

Radi ZA, Koza-Taylor PH, Bell RR, Obert LA, Runnels HA, Beebe JS, Lawton MP and Sadis S (2011) Increased serum enzyme levels associated with Kupffer cell reduction with no signs of hepatic or skeletal muscle injury. Am J Pathol 179: 240-247.

Ries CH, Cannarile MA, Hoves S, Benz J, Wartha K, Runza V, Rey-Giraud F, Pradel LP, Feuerhake F, Klaman I, et al. (2014) Targeting tumor-associated macrophages with anti-CSF-1R antibody reveals a strategy for cancer therapy. Cancer Cell 25: 846-859.

Smit MJ, Beekhuis H, Duursma AM, Bouma JM, and Gruber M (1988) Catabolism of circulating enzymes: plasma clearance, endocytosis, and breakdown of lactate dehydrogenase-1 in rabbits. Clin Chem 34:2475-2480.

Smit MJ, Duursma AM, Bouma JM, and Gruber M (1987) Receptor-mediated endocytosis of lactate dehydrogenase M4 by liver macrophages: a mechanism for elimination of enzymes from plasma. Evidence for competition by creatine kinase MM, adenylate kinase, malate, and alcohol dehydrogenase. J Biol Chem 262: $13020-13026$.

Smit MJ, Wijnholds J, Duursma AM, Bouma JM, and Gruber M (1986) Plasma clearance of mitochondrial aspartate aminotransferase in the rat: competition with mitochondrial malate dehydrogenase. Biomed Biochim Acta 45:1557-1561.

Smoller BR and Hiatt KM (2009) Dermatopathology: The Basics, Springer Verlag.

Staals EL, Ferrari S, Donati DM, and Palmerini E (2016) Diffuse-type tenosynovial giant cell tumour: current treatment concepts and future perspectives. Eur $J$ Cancer 63:34-40.

Stacchiotti S, Crippa F, Messina A, Pilotti S, Gronchi A, Blay JY, and Casali PG (2013) Response to imatinib in villonodular pigmented synovitis (PVNS) resistant to nilotinib. Clin Sarcoma Res 3:8.

Stanley ER and Chitu V (2014) CSF-1 receptor signaling in myeloid cells. Cold Spring Harb Perspect Biol 6.

Tap WD, Wainberg ZA, Anthony SP, Ibrahim PN, Zhang C, Healey JH, Chmielowski B, Staddon AP, Cohn AL, Shapiro GI, et al. (2015) Structure-guided blockade of CSF1R kinase in tenosynovial giant-cell tumor. $N$ Engl J Med 373: 428-437.

Verma RP and Hansch C (2007) Matrix metalloproteinases (MMPs): chemicalbiological functions and (Q)SARs. Bioorg Med Chem 15:2223-2268.

Wang T, Papoutsi M, Wiesmann M, DeCristofaro M, Keselica MC, Skuba E, Spaet R, Markovits J, Wolf A, Moulin P, et al. (2011) Investigation of correlation among safety biomarkers in serum, histopathological examination, and toxicogenomics. Int $J$ Toxicol 30:300-312.

West RB, Rubin BP, Miller MA, Subramanian S, Kaygusuz G, Montgomery K, Zhu S, Marinelli RJ, De Luca A, Downs-Kelly E, et al. (2006) A landscape effect in tenosynovial giant-cell tumor from activation of CSF1 expression by a translocation in a minority of tumor cells. Proc Natl Acad Sci USA 103:690-695.

Wheater G, Elshahaly M, Tuck SP, Datta HK, and van Laar JM (2013) The clinical utility of bone marker measurements in osteoporosis. J Transl Med 11:201.

Zhang L, Beal SL, and Sheiner LB (2003) Simultaneous vs. sequential analysis for population PK/PD data I: best-case performance. J Pharmacokinet Pharmacodyn 30:387-404.

Address correspondence to: Ursula Schramm, Novartis Pharma AG, CH-4056 Basel, Switzerland. E-mail: ursula.schramm@novartis.com 